\title{
أثر تقلبات سعر الصرف على الميزان التجاري لقطاع الأدوية المصري (دراسة تطبيقة)
}

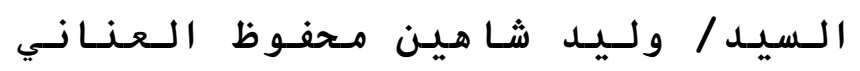

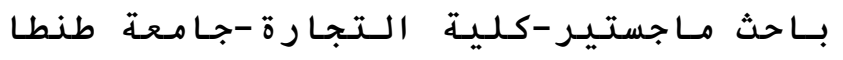

\author{
تحت اشراف \\ ا .م ـ د / أشرف لـطفي الـسيـد بـدوى \\ ا .م ـد /سمـر الأمـيـر غـازي عبـد الـحمـيـد
}

https://caf.journals.ekb.eg/ 

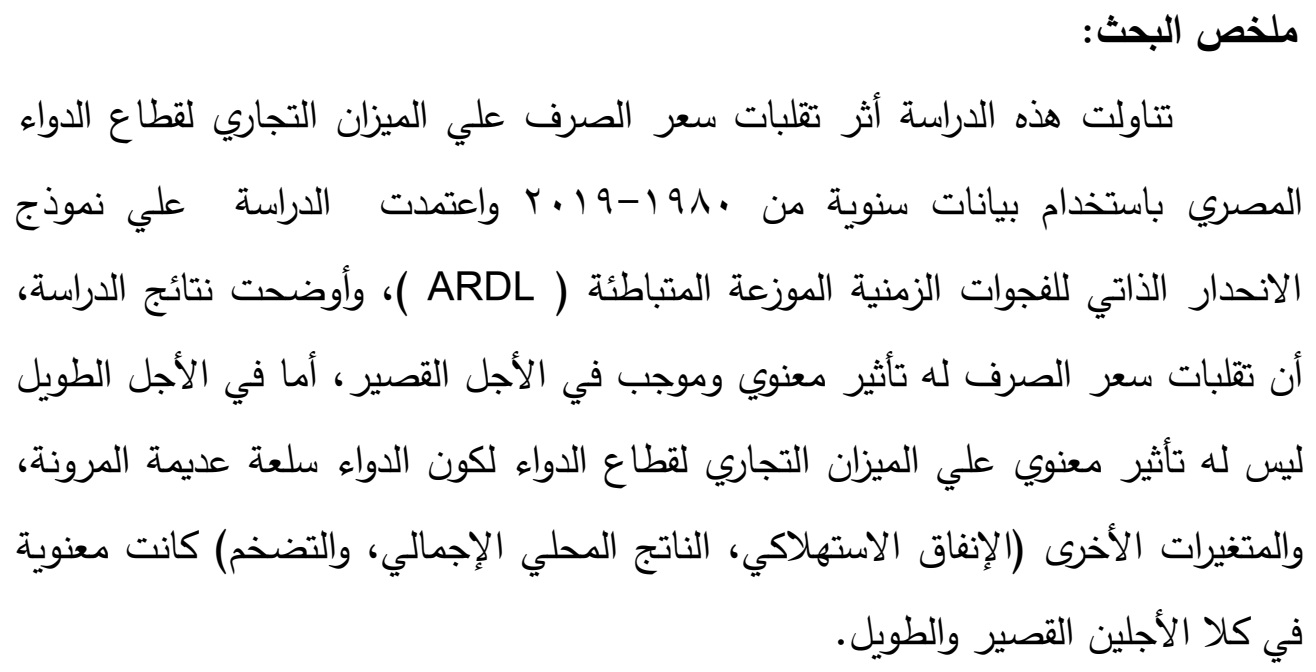

\begin{abstract}
This study examined the effect of exchange rate fluctuations on the trade balance of the Egyptian pharmaceutical sector, using annual data from 1980-2019.The study relied on the autoregressive Distributed lag model The volatility of exchange rate has a positive and significant effect in the short term, but in the long term it does not have a significant effect on the trade balance of the medicine sector because medicine is an inflexible commodity, other variables (Consumer spending, Gross domestic product, Inflation) were significant in both short and long-term.
\end{abstract}

Key words: exchange rate, trade balance, pharmaceutical industry, ARDL. 


\section{1 -المقدمة:}

يعد سعر الصرف أحد المؤشرات الاقتصادية والمالية الهامة التي تعبر عن قوة

وجودة الأداء الاقتصادي للدول، ويمثل سعر الصرف العمود الفقري الذي تعتمد عليه اقتصاديات أي دولة من دول العالم، سواء كانت من الدول المتقدمة أو النامية، لذلك تسعى معظم الدول لوضع سياسات تهدف إلى ضمان استقرار سعر صرف عملاتها؛ لان استقراره يعتبر مؤشرا مهما لمدى تطور وتقدم واستقرار اقتصاد الدولة، وأيضا لتفادي تلك الدول التقلبات الحادة التي تمر بها العملات من فترة لأخرى، ويتعاظم هذا الدور في الدول النامية لأن معظم هذه الدول تعاني من انفتاح اقتصادياتها بشكل كبير، مما يجعلها أكثر تأثرا بالتقلبات الاقتصادية الدولية، مما ينعكس سلبا على درجة الاستقرار المحلي فيه، ويؤكد بعض علماء الاقتصاد بأن تقلبات سعر الصرف في التجارة قد يؤثر بالسلب أو الإيجاب معتمدا علي السلوك السيكولوجى (الذي تعتبر درجة المخاطر دالة فيه) للصصدرين والمستوردين (سليمان،9 ( • (Y). كما يمكننا تعريف تقلبات سعر الصرف بأنها تلك المخاطر التي تصاحب التحركات غير المتوقعة في سعر الصرف؛ ولذا يعتبر التقلب في أسعار الصرف هو مصدر للمخاطر التي تكون لها تأثيرات ضمنية مؤكدة على حجم التجارة

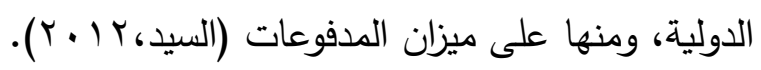

ولقد تتوعت الأدبيات التي حاولت تفسير العلاقة بين أثار تقلبات سعر الصرف

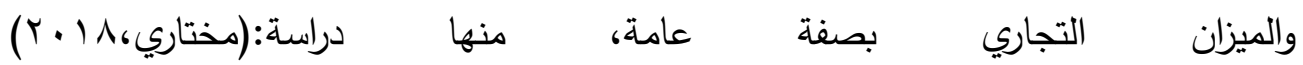
و(سليمان، 1 • (Y)و(Ayobami, 2019) و(Thuy,2019)، وندرت الأدبيات التي سعت لتفسير العلاقة بين تقلبات سعر الصرف والميزان التجاري لقطاع الدواء المصري، لذلك حاول الباحث تفسير تلك العلاقة بين تقلبات سعر الصرف والميزان التجاري لقطاع الدواء، وحيث أن قطاع الدواء؛ يعد من القطاعات الحيوية؛ لذا سنتطرق بشكل عملي مختصر وبالأرقام في الجدول التالي: للميزان التجاري لقطاع الدواء المصري، موضحا صادرات 
وواردات الدواء المصري ونسبة النمو فيهما، وأيضا نسبة التغطية والفجوة الدوائية للفترة من

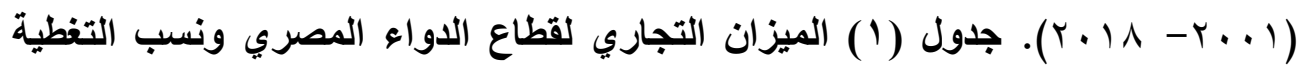

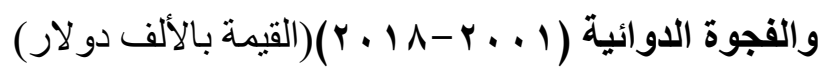

\begin{tabular}{|c|c|c|c|c|c|c|c|}
\hline الدوائية & التغطبة & في الواردات النمو & في الصبة النمو & من الميزات التجرى الادوية & من اردات مصدير & صسادرات مصر من الأدويـة & السنة \\
\hline$\% \wedge \bullet, \wedge \vee$ & $\% 1 \leq, 1 r$ & & & $r q V, r \leq r-$ & $r \leq 7,101$ & $\varepsilon \wedge, 910$ & $r \ldots$ \\
\hline$\% \wedge \varepsilon, \cdot r$ & $\% 10,9 \wedge$ & $\%$, ᄉ, or & \%rr, q a & $r \leq \varepsilon, V 1 \leq-$ & $\leqslant 1,, r \circ 4$ & $70,0 \leq r$ & $r \cdot r$ \\
\hline$\% \wedge r, \cdot r$ & $\% 17,9 \vee$ & $\%$ \%, $0 \leq-$ & $\%$ \% , IV- & $r \leq \ldots, \ldots v-$ & $r \wedge 9, .00$ & $\leq 9, \cdot \leq \wedge$ & $r . . r$ \\
\hline$\% \wedge 0,1 \vee$ & $\% 1 \leq, \wedge r$ & $\% \cdot, 1 \cdot-$ & $\% \backslash r, v \cdot-$ & $r \leq 0,9 \leq 0-$ & 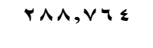 & $\varepsilon r, \wedge, q$ & $r \ldots \varepsilon$ \\
\hline$\% \vee a, \leq 1$ & $\% r \cdot, 09$ & $\% a$, or & $\% \circ r, .7$ & rol, $1 \leq 4$ & rI $7, r \circ V$ & 70,11 & $r . .0$ \\
\hline$\% \vee \leq, \wedge r$ & $\%$ \%०, 1 & $\%$ \%., 1.- & $\%$ \%, ২^ー & 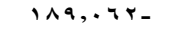 & ror,791 & $7+7 \times 9$ & $r . . T$ \\
\hline$\% \vee r, q \wedge$ & $\% r v, \cdot r$ & $\%$ \% , ^ & $\% \leq 0, v r$ & ro., $\leqslant 0 .-$ & $r \leqslant r, I v v$ & $Q r, v r v$ & $r \cdot v$ \\
\hline$\% \wedge$ \%, ч. & $\%$ \, <. & $\% \backslash \neg \wedge, \diamond 9$ & $\% \wedge r, 9 r$ & vor, $\cdots$ & ari,Vrr & $179,7 r 4$ & $r \cdot \lambda$ \\
\hline$\% \vee 7,0$. & $\%$ \%r,o. & $\%$ Ir, IV & $\% \leq r, r)$ & va1,.।1- & דים, 1, ו & $r \leq r, q r O$ & $r . . q$ \\
\hline$\% \vee 7,0 \leq$ & $\%$ \%r, $\leq 7$ & $\% 1, \wedge 7$ & $\% 1, v r$ & $\wedge, 7, \cdot \vee 1-$ & $1, .0 r, 1 \vee 1$ & $r \leq v, 1 \ldots$ & $r \cdot 1$. \\
\hline$\% \wedge 1,79$ & $\% \backslash \wedge, \hookleftarrow$, & $\%$ \%^,rч & $\% \cdot, 10$ & $1,1 . \leq, r a 9-$ & $1, r \circ 1, \wedge \vee v$ & $r \leq \vee, \varepsilon \vee \wedge$ & 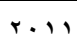 \\
\hline$\% \wedge 1, q \leq$ & $\% \backslash \wedge, . ૫$ & $\%$ \%r,v^ & $\% r r, 1 r$ & $1, r v 1,1.1-$ & יזr, 1, & $r \cdot r, r r$ & $r \cdot r$ \\
\hline$\% \wedge 1, \leq r$ & $\% \wedge \wedge, \diamond \wedge$ & $\% \vee, q 0$ & $\% 11, \cdot v$ & $1, \varepsilon \vee \cdot, \vee 10-$ & $1, \wedge \cdot 7, \varepsilon \cdot 7$ & rro,79ו & $r \cdot 1 r$ \\
\hline$\% \wedge,, r \leq$ & $\%$ \%, ૫ & $\% \leq, 0 \wedge$ & $\% 0, \cdot r$ & 1,Or4,OV1- & 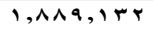 & ror,orl & $r \cdot 1 \leq$ \\
\hline$\% \wedge \wedge, \wedge ґ$ & $\% 1,1 v$ & $\% r \cdot, r q$ & $\% r v, a v-$ & $r, \cdot r \cdot, r q \vee=$ & $r, r v \leq, r \circ r$ & ror,904 & $r .10$ \\
\hline$\% \wedge \leq, 97$ & $\% 10, . \leq$ & $\%$ ।, , $0-$ & $\%$, r, o. & $1, \tau r v, v \leq 0-$ & $1,910,99$. & $r \wedge \wedge, r \leq 0$ & 5.17 \\
\hline$\% \wedge \vee, r a$ & $\%$ & $\% 1 \leq, 19$ & $\% \leq, r,-$ & $1, q 1,+, 0 \cdot-$ & $r, 1 \wedge \vee, \wedge q q$ & $r \vee 0, \wedge \leq q$ & $r \cdot i r$ \\
\hline$\% \wedge a, r \curlyvee$ & $\% 1 \cdot, 7 \wedge$ & $\% 0,0 r$ & $\% 1 \cdot, 7-$ & $r, . r r, r^{\prime} r_{-}$ & $r, r \cdot \wedge, \wedge \vee \wedge$ & $r \leq 7, O \wedge r$ & $r \cdot 1 \wedge$ \\
\hline
\end{tabular}

Sources: ITC calculations based on UN بواسطة الباحث بالاعتماد على

COMTRADE and ITC statistics

نسبة تغطية الصادرات للواردات = (الصادرات / الواردات )\%، حجم الفجوة = . . 1 نسبة التغطية، درجة الانفتاح الاقتصادي تبين درجة الأهمية النسبية للتجارة الخارجية أو درجة انكشاف الاقتصاد علي العالم الخارجي ومدي ارتباطه به ودرجة 
انفتاحه عليه وتحسب بالمعادلة (درجة الانفتاح الاقتصادي = (الصادرات السلعية +

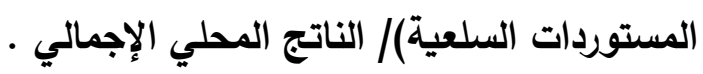

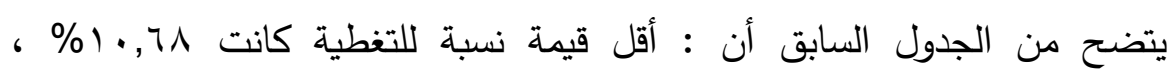

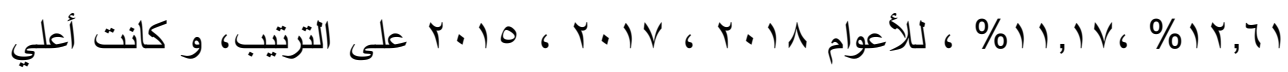

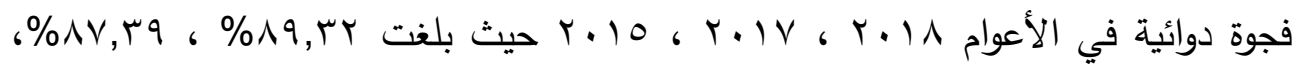

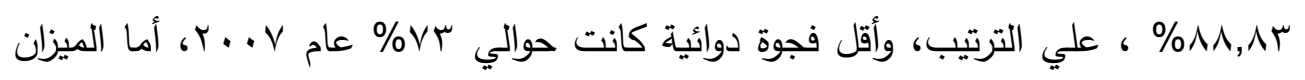

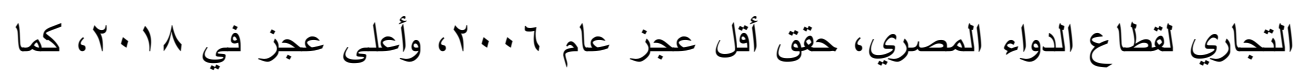
يتضح من الجدول السابق( مركز التجارة العالمي،9 ( ـ ب).

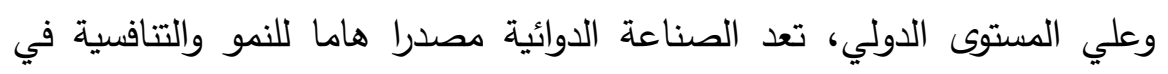

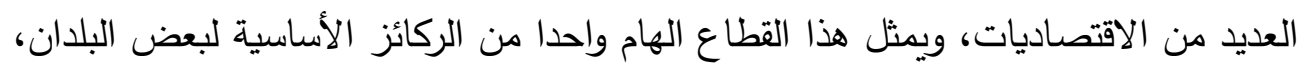

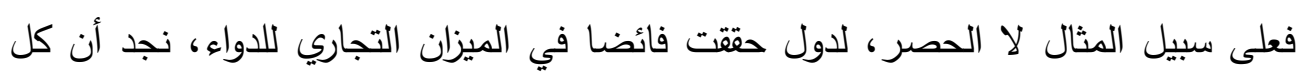

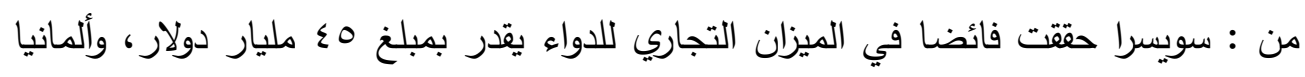

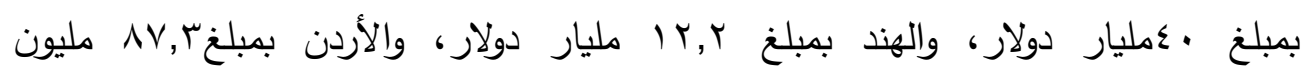

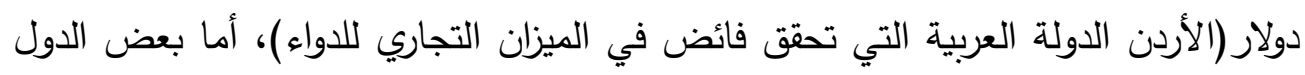

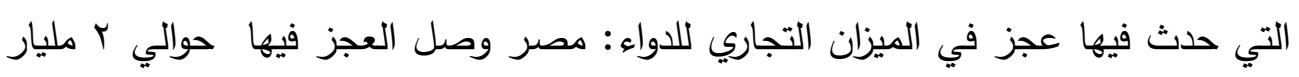
دولار، والسعودية وصل العجز r ب,0 مليار دولار، من نفس العام(مركز التجارة العالمي،

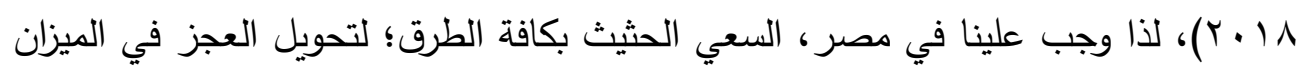

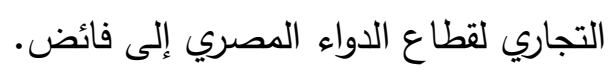
r-مشكلة البحث:

إن التغيرات الاقتصادية التي طرأت على المشهد المصري في السنوات الأخيرة، كالقرار الذي

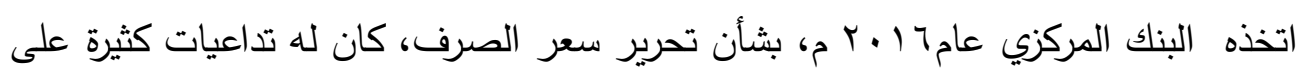

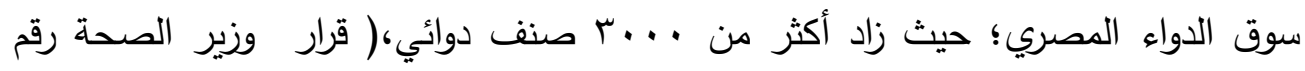




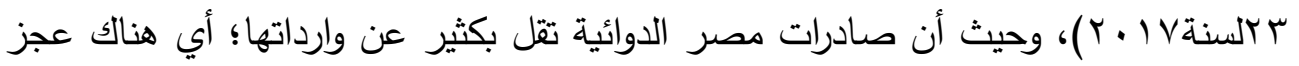
بالميزان التجاري للدواء المصري - كما هو موضح بالجدول رقم (1)، ومن أسباب هذا العجز؛ أن الدول النامية ومنها مصر لا تمتلك قاعدة صناعية كبيرة قادرة على المنافسة الخارجية عامة، وفى قطاع الأدوية خاصة لأسباب كثيرة منها؛ أن معظم مكونات الدواء مستوردة من الخارج). لذا كان قرار التعويم، وما كان لله من تداعيات كثيرة، وظهور كثير من الآراء بين مؤيد ومعارض؛ بشان قرار البنك المركزي بتحرير سعر الصرف ، كان من أهم الأسباب؛ لمعرفة تأثير تقلبات سعر الصرف علي الميزان التجاري لقطاع الدواء المصري. وفيما يلي رسم بياني يوضح تطور كل من : الميزان التجاري لقطاع الدواء المصري، وتقلبات سعر صرف الجنيه المصري. TB

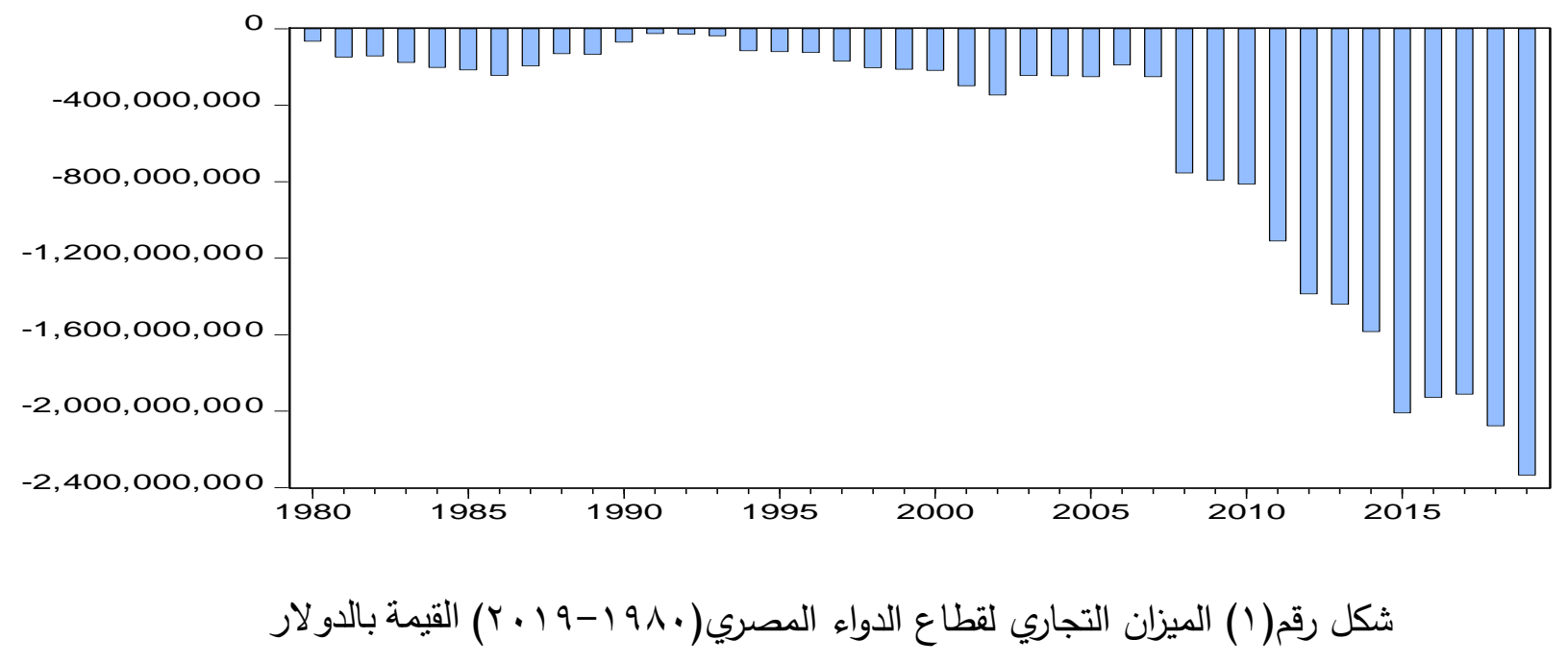


المصدر: الجهاز المركزي للإحصاء

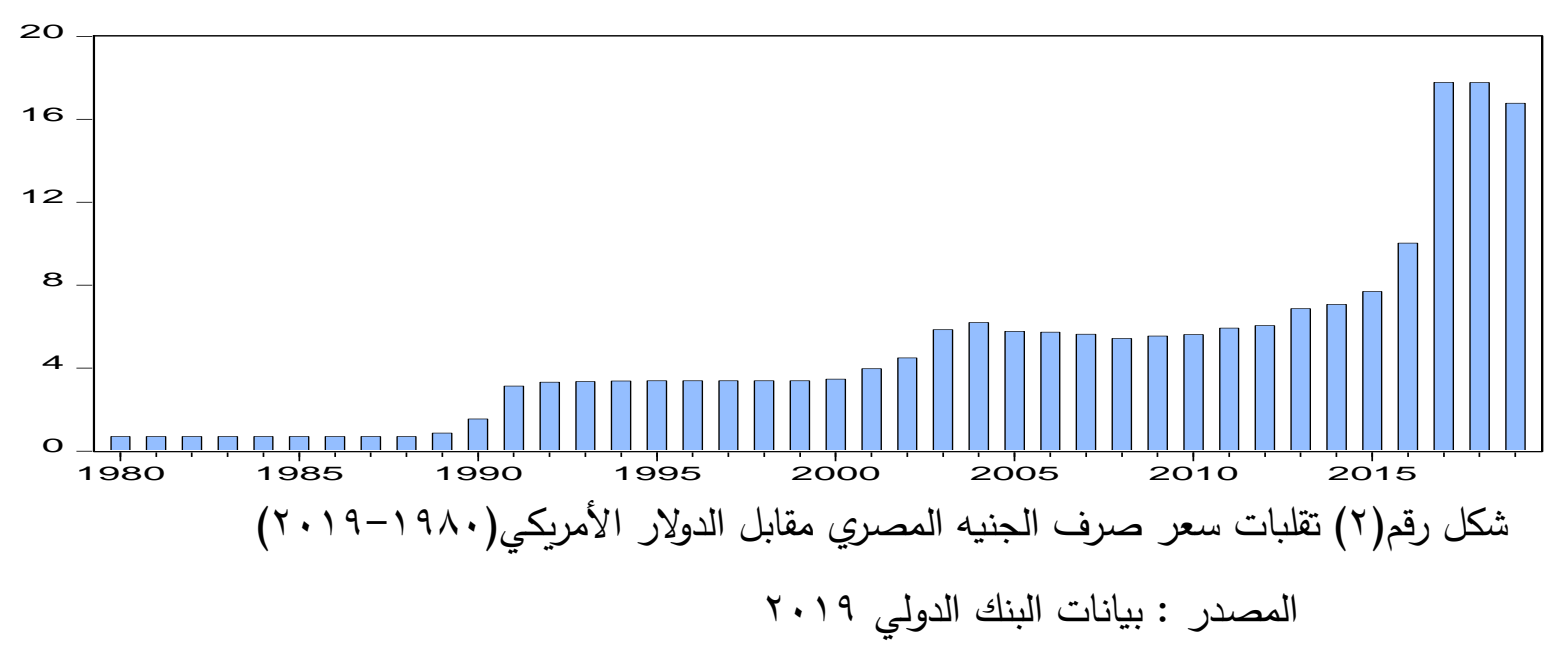

ومن خلال ما سبق تتمثل المشكلة البحثية في السؤال التالي:

ما مدى تأثير تقلبات سعر الصرف على الميزان التجاري لقطاع الدواء المصري؟ وتتطرق الدراسة إلى معرفة:-

تأثير الناتج المحلي الإجمالي على الميزان التجاري للدواء، وتأثير الإنفاق الاستهلاكي على الميزان التجاري للدواء، و تأثير التضخم على الميزان التجاري للدواء.

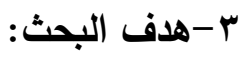

قياس أثر تقلبات سعر الصرف على الميزان التجاري لقطاع الدواء المصري للفترة

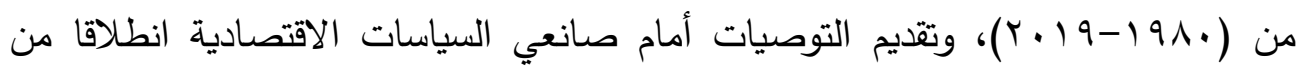
النتائج التي سنصل إليها من تقدير وتحليل النموذج، وذلك بما يتلاءم مع خصائص وظروف

الاقتصاد المصري.

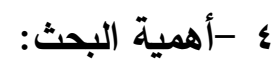

تكمن أهمية البحث في النقاط التالية:-

ا-يعد سعر الصرف حلقة الوصل في العلاقات الدولية، ومتغير اقتصادي 


$$
\text { محوري في النشاط الاقتصادي، كونه من المؤشرات الاقتصادية الهامة، حيث تسعى الدول للمحافظة علي استقراره. }
$$

التقلبات في سعر الصرف قد توثر على توازن الميزان التجاري لقطاع الدواء الذي يمثل قطاعا هاما ومحوريا، لما للدواء من أهمية قصوى من الجانب الصحي، ومن الجانب الاقتصادي يمثل سلعة قليلة المرونة، وخدمة في نفس الوقت؛ لذا تعد هذه الدراسة من الدراسات المهمة والنادرة التي تسلط الضوء على أثر تقلبات سعر الصرف على الميزان التجاري لقطاع الأدوية، خصوصا في السنوات الأخيرة التي شهدت تحريرا في سعر الصرف.

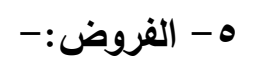

$$
\text { يعتمد البحث على فرض أساسي و هو: }
$$

لا يوجد تأثير ذو دلالة إحصائية بين تقلبات سعر الصرف والميزان التجاري للدواء.

ومنه تنبثق الفروض الفرعية التالية :

ا - لا يوجد تأثير ذو دلالة إحصائية بين الناتج المحلي الإجمالي والميزان التجاري للدواء. r- لا يوجد تأثير ذو دلالة إحصائية بين الإنفاق الاستهلاكي والميزان التجاري للدواء. r- لا يوجد تأثير ذو دلالة إحصائية بين التضخم والميزان التجاري للدواء.

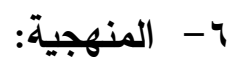

يعتمد البحث على كل من : المنهج الوصفي التحليلي؛ للإحاطة بالجوانب النظرية للدراسة، والمنهج القياسي؛ لقياس أثر تقلبات سعر الصرف علي الميزان التجاري للدواء المصري للفترة الدراسة ، مع الاستعانة بالبيانات المتاحة للمؤشرات الاقتصادية، وأي مصدر معتمد بالإضافة إلى ما كتب في هذا المجال .

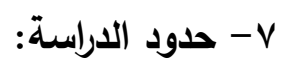

الحدود المكانية: قطاع الدواء في جمهورية مصر العربية

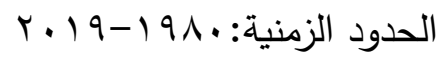

1- الاراسات السابقة :- 


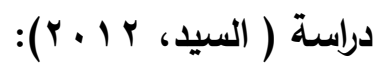

هدفت الدراسة إلى التحقق من العلاقة بين الصادرات المصرية وبين كل من

التقلبات في سعر صرف الجنية المصري، وسعر الصرف الفعال، الدخل العالمي، ومعدلات التبادل الدولي. (وذلك في الأجلين القصير والطويل ). باستخدام بيانات ربع سنوية للفترة من •9191 1- • • • . . ولتحقق من هدف الدراسة تم تطبيق نموذجي تصحيح الخطأ(ECM) والانحدار الذاتي(VAR)، وأوضحت الدراسة القياسية أن جميع متغيرات الدراسة متكاملة فيما بينها خلال فترة الدراسة، بمعنى أن هذه المتغيرات لن تتحرف كثيرا في الأجل الطويل، كذلك وجد أن هناك علاقة سلبية بين التقلبات في سعر الصرف وحجم الصادرات في كلا الأجلين القصير والطويل.

$$
\text { دراسة ( عبدا لحميد، IV P P ) }
$$

عمدت الدراسة إلى معرفة أثر تغيرات سعر الصرف على ميزان المدفوعات المصري وبعض المتغيرات الاقتصادية الأخرى مثل الناتج المحلى الحقيقي في إطار

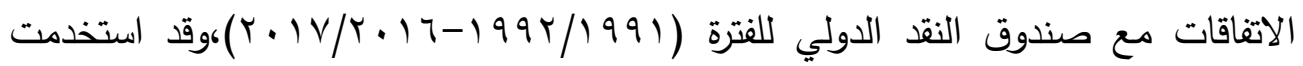
الدراسة المنهج الوصفي والمنهج القياسي في التحليل ونموذج الانحدار المتعدد، ومن أهم ما توصلت إليه الدراسة من نتائج، توجد علاقة عكسية معنوية بين سعر الصرف وفائض ميزان المدفوعات، وأن الناتج المحلى الإجمالي تأثيره غير معنوي على فائض ميزان المدفوعات.

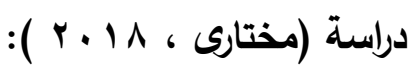

هدفت هذه الدراسة إلى معرفة أثز تقلبات سعر الصرف على الميزان التجاري وآليات علاجها، من خلال التطرق للجانب النظري لسعر الصرف والميزان التجاري، إيضاح أثر تقلبات سعر الصرف على الميزان التجاري، إبراز آليات معالجة تقلبات سعر الصرف على الميزان التجاري وإمكانية تطبيقها على الدول النامية،انطلاقا من خصائص كل دولة ومدى استقرار عملتها مقابل العملات الأخرى، وقد اتبع الباحث المنهج الوصفي والإستقرائى، 
ومن أهم ما توصلت إليه الدراسة من نتائج تعرض سعر الصرف لتغيرات مستمرة نتيجة لعوامل اقتصادية وغير اقتصادية لها تأثير على الميزان التجاري.

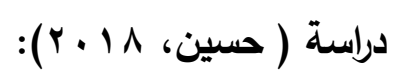

قامت الدراسة بمعرفة الآثار الايجابية أو السلبية لتغيرات سعر صرف الدينار

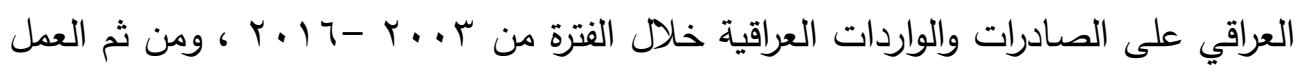
على معالجة ذلك. وقد استخدم الباحث المنهج الوصفي بأدواته، مستخدما نموذج جوهانسن

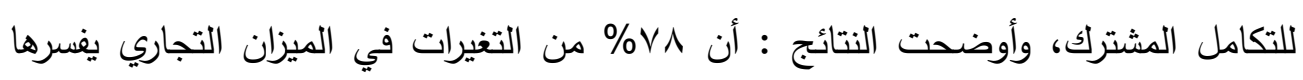

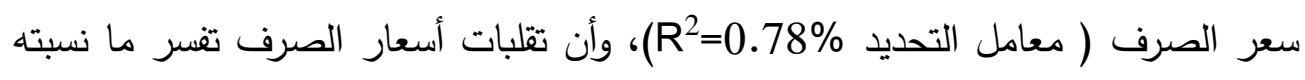

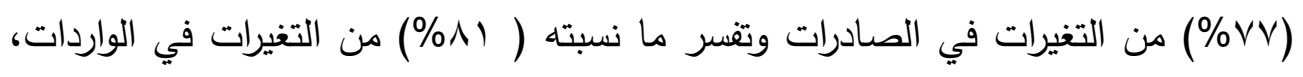

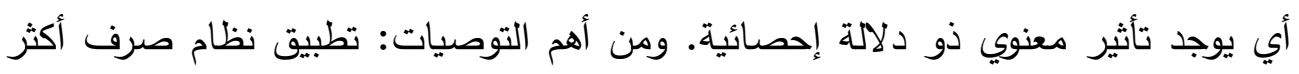

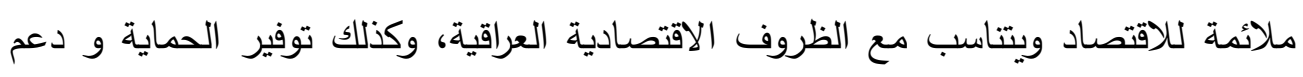
القطاعات الإنتاجية لتقليل الاعتماد على الخارج.

دراسة (Motlagh,et al.,2018):

هدفت الدراسة إلى التحقق من أثار تتلبات سعر الصرف على استيراد وتصدير

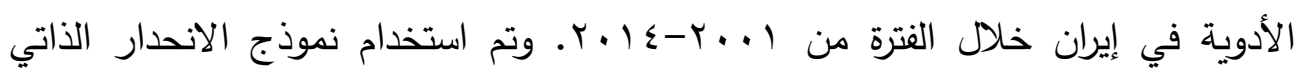
المتكامل والمتوسط المتحرك (ARIMA)، أو نموذج بوكس - جينكز، واستخدمت متغيرات،

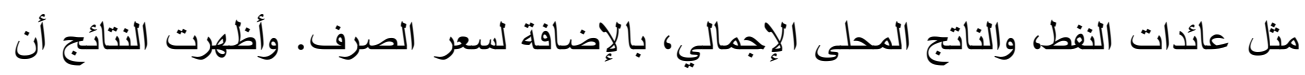

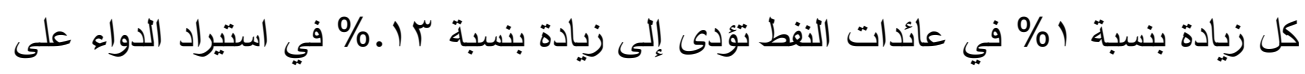

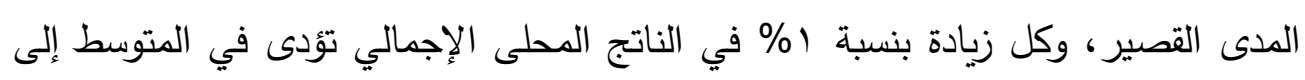

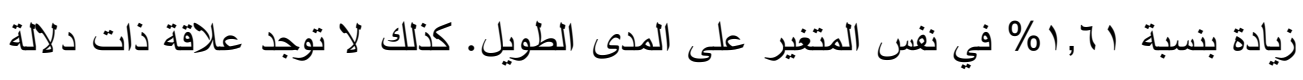

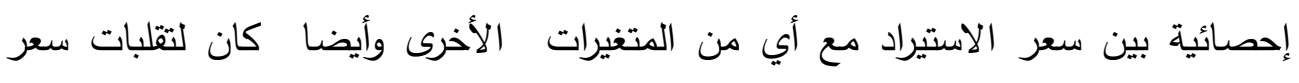


الصرف تأثير عكسي على صادرات الأدوية،حيث أن زيادة ا \% في تقلبات سعر الصرف

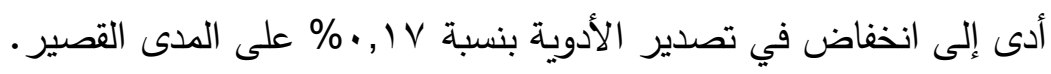
دراسة ( Tumturk,2018):

ناقثت الدراسة البحث في الآثار طويلة الأجل لتقلبات أسعار الصرف على

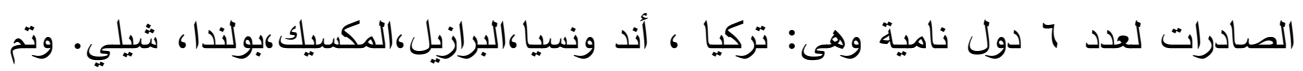

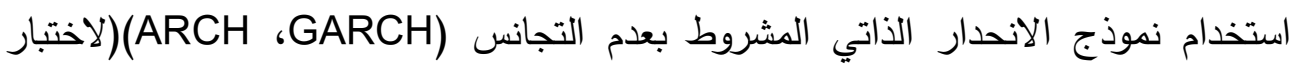

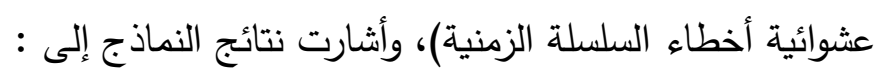
1- لا توجد علاقة تكامل مشترك بين البرازيل واندونيسيا وشيلي بينما توجد علاقة تكامل مشترك بين تركيا والمكسيك وبولندا. r- الدخل العالمي هو المحدد الرئيسي الذي يقود أحجام الصادرات في تركيا والمكسيك ترديك وبولندا.

1- يوجد اثر سالب ومعنوي بين سعر الصرف الصادرات في بولندا،وايجابي في تركيا.

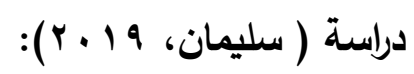

تناولت الدراسة تحليل تطورات سعر الصرف و معرفة أثر تقلباته على الصادرات

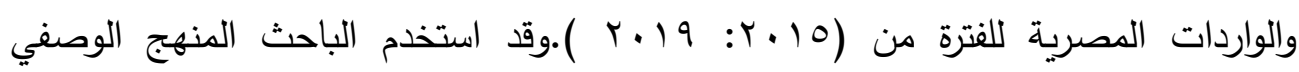

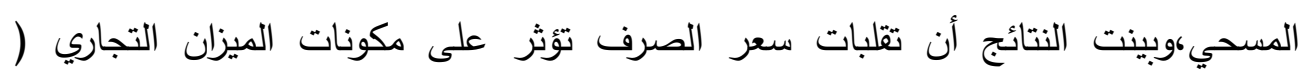

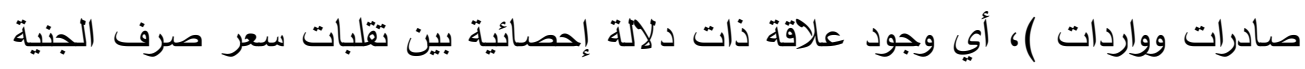
الدصري و قيمة الصادرات والواردات، ومن أهم ما أوصت به الدراسة: 1- تفعيل نظام صرف أكثر ملائمة للاقتصاد المصري. r- العمل على الحد من الاستيراد قدر الإمكان، وإتباع سياسة جمركية إيجابية. 
r- توفير كافة سبل لتمويل المشاريع الإنتاجية الإستراتجية القادرة على النهوض بالقطاعات الإنتاجية الحيوية لتحقيق زيادة في الصادرات وبالتالي زيادة مساهمتها في تتمية الاقتصاد.

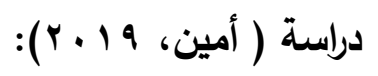

هدفت الدراسة إلى معرفة أثر سياسة تخفيض العملة على الواردات الجزائرية من

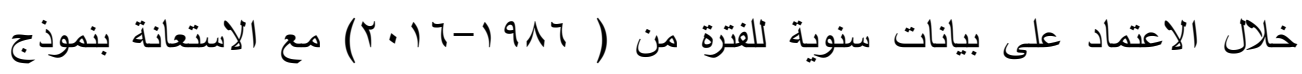
الانحدار الذاتي، ومن أهم النتائج التي توصلت لها الدراسة أن التغير في الواردات الجزائرية يثكل قيما مرنة لتغير سعر الصرف الحقيقي، كما أظهرت أن العلاقة بينهما طردية، حيث أن زيادة سعر الصرف الحقيقي يؤدى لزيادة أسعار السلع المحلية مقارنة بالأجنبية وهذا بدوره يؤدى لزيادة الواردات،وبما أن جزاء كبيرا من السلع المستوردة يشمل على سلع غذائية

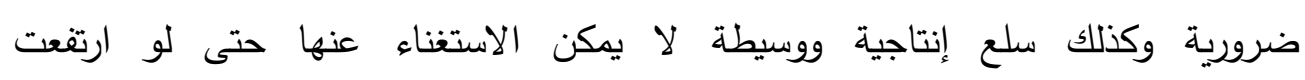
أسعارها،ولذلك فإن سياسة التخفيض لم تؤت ثمارها في الحد من الواردات.

$$
\text { دراسة ( عبدا لرحمن ، } 9 \text { ( • ب ) ): }
$$

هدفت الدراسة لمعرفة أثر تقلبات سعر الصرف الحقيقي لليوان الصيني مقابل الدولار الأمريكي على صادرات الصين إلى الولايات المتحدة الأمريكية خلال الفترة ( .... ب1 • (Y)، وتم استخدام نموذج الانحدار البسيط بالاعتماد على برنامج (Eviews09)، واعتمد على طريقة المربعات الصغرى في تقدير النموذج، وتوصلت الدراسة إلى وجود علاقة عكسية بين سعر الصرف الحقيقي لليوان الصيني مقابل الدولار الأمريكي وصادرات الصين إلى أمريكا، حيث وجد أن هناك انخفاضات متتالية سجلها سعر الصرف الحقيقي لليوان الصيني مقابل الدولار الأمريكي خلال فترة الدراسة،وفى الجهة الأخرى هناك تزايدا جليا سجلتها صادرات الصين إلى الولايات المتحدة. دراسة ( Chaudhry,2019): 
هدفت الدراسة البحث في تأثير تقلبات أسعار الصرف على إجمالي الصادرات والواردات الكندية والصادرات إلى الولايات المتحدة الأمريكية والواردات منها. وتم استخدام النموذج المعمم للانحدار الذاتي المشروط بعدم ثبات التباين (GARCH).واستخدام بيانات

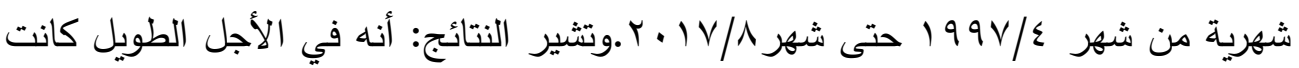
هناك علاقة عكسية بين تقلبات سعر الصرف وبين إجمالي الصادرات الكندية عامة، والصادرات إلى أمريكا خاصة، ولكن العلاقة بين تقلبات سعر الصرف وواردات كندا من أمريكا كانت علاقة عكسية ضعيفة. ومن أهم التوصيات: أنه يجب على صانعي السياسات السعي قدما لإقامة علاقة توازن قصيرةوطويلة الأجل بين تقلبات سعر الصرف والصادرات والواردات.

دراسة (Saqib,2019):

هدفت الدراسة إلى تقييم ومقارنة التأثير المتماثل والغير متماثل في المدى الطويل والقصير لتقلبات سعر الصرف على التدفقات التجارية المصنفة على مستوى الصناعة في باكستان. وتم استخدام بيانات ربع سنوية للفترة من الربع الثالث لعام r . . ب وحتى الربع

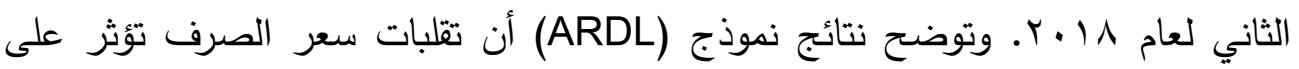
تدفقات التجارة بشكل سلبي لبعض الصناعات وبشكل إيجابي لأخرى، وذلك في كلا الأجلين القصير والطويل. دراسة ( Thuy,2019):

تتاولت الدراسة البحث في أثر تقلبات سعر الصرف على صادرات فيتام، باستخدام بيانات

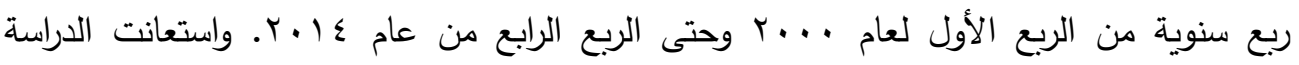

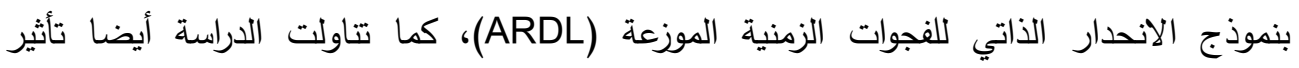

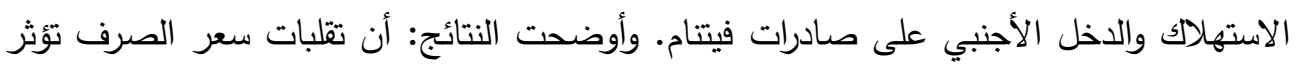
سلبا على حجم الصادرات في الأجل الطويل. ويؤثر تخفيض قيمة العملة المحلية على الصادرات سلبا في الأجل القصير الجن 
دراسة (Mmelesi, et al, 2019):

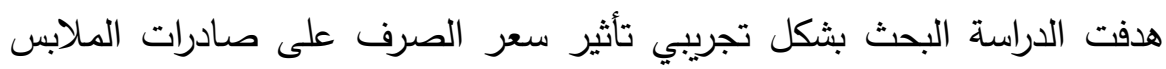

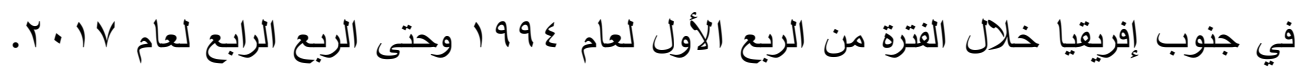

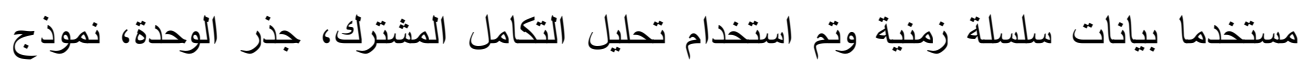

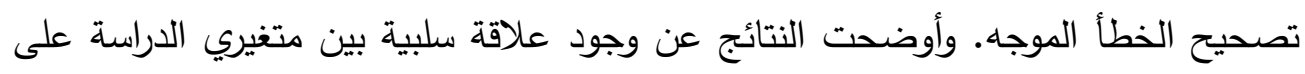

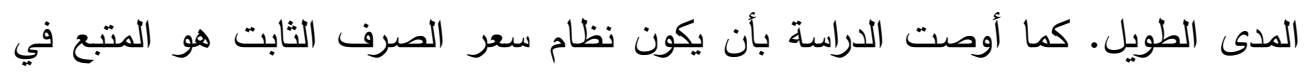
جنوب إفريقيا.

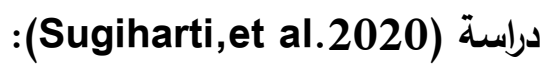

هدفت الدراسة البحث في تأثير تقلبات سعر الصرف على صادرات السلع الأولية في أند ونسيا لأعلى خمس أسواق (الولايات المتحدة، اليابان، الصين، الهنات الهات، كوريا الجنوبية). وتم استخدام النموذج المعدم للانحدار الذاتي المشروط بعدم ثبات التبات التباين (GARCH)

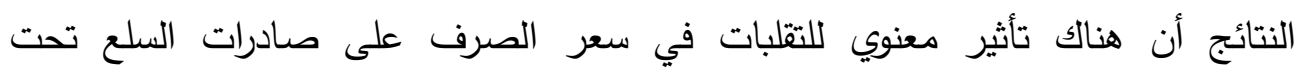

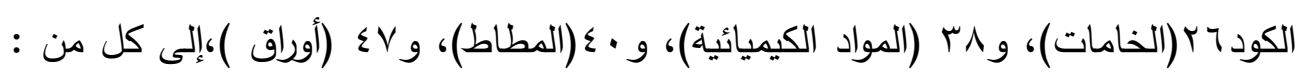

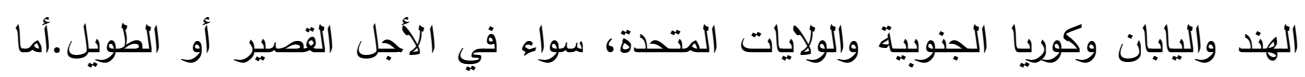

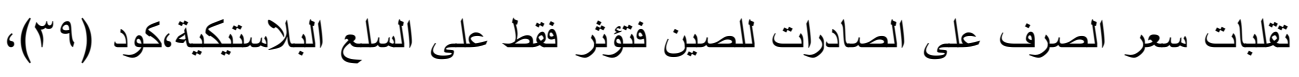

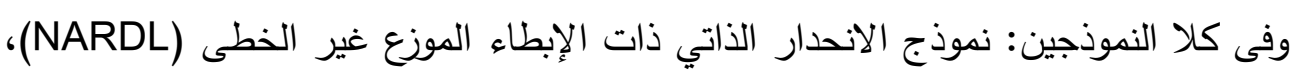

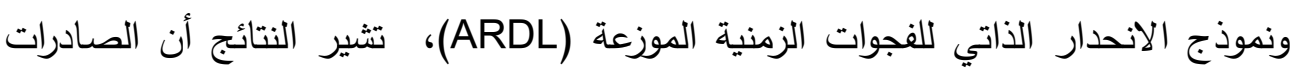

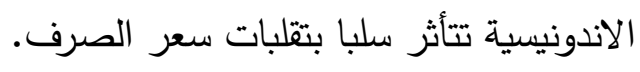

دراسة (Ayobami, 2019)

تناولت الدراسة تأثير تقلب سعر الصرف على أداء قطاع الصناعات التحويلية في

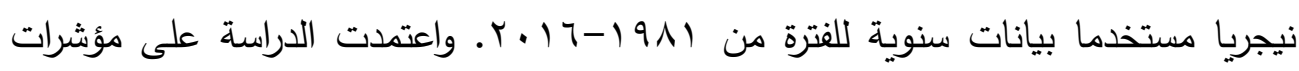
التنمية للبنك الدولي، والنشرة الإحصائية للبنك المركزي في نيجريا للحصول علي البيانات،

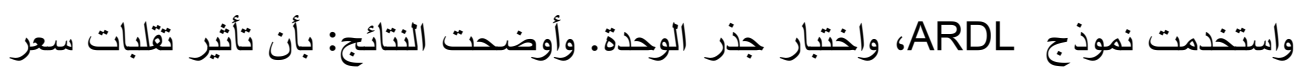

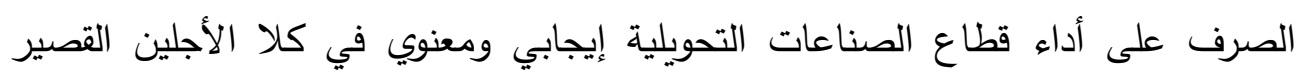


والطويل، إضافة إلي ذلك أوضحت الدراسة تأثير سعر الصرف على إنتاج قطاع الصناعات التحويلية إيجابي وغير معنوي في الأجل الطويل بينما سلبي ومعنوي في الأجل القصير. وتأثير الاستيراد على القطاع سلبي ومعنويا في كلا الأجلين. دراسة (Emmanuel. K.,2019):بحثت الدراسة تأثير تقلب سعر الصرف الحقيقي

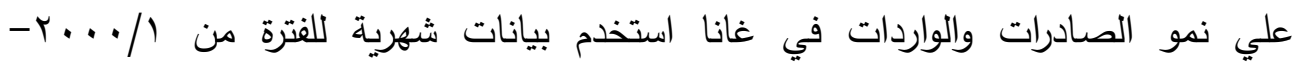

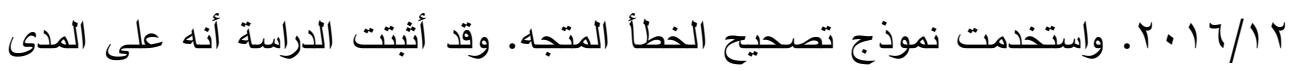
الطويل كان انخفاض سعر الصرف الحقيقي وزيادة التقلب وزيادة نمو الإنتاج من العوامل الهامة التي زادت من نمو الصادرات، أيضا كان انخفاض تقلب سعر الصرف الحقيقي نمو الإنتاج الصناعي من العوامل الهامة التي يمكن أن تقلل من نمو الاستيراد، و بالرغم من ذلك كان انخفاض سعر الصرف الحقيقي وانخفاض تقلب سعر الصرف الحقيقي في الددى القصير من العوامل الهامة التي يمكن أن تزيد من نمو الصادرات، و أيضا انخفاض سعر

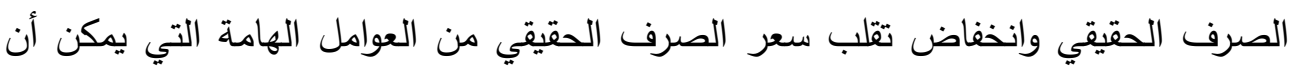

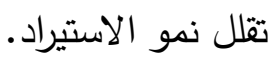
دراسة (Bahmani-Oskooee, M., \& Nouira,2019) قام البحث على اختبار التأثيرات المتماثلة وغير المتماثلة لتقلب سعر الصرف على الى التجارة الثائية بين تونس وشركائها الستة عشر (فرنسا، ايطاليا، ألمانيا، الصين، اسبانيا، الجزائر، تركيا، أمريكا، روسيا، انجلترا، بلجيكا، الهند، هولندا ،سويسرا، بولندا، المغرب )

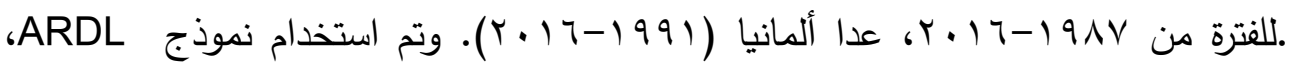
ووجد أن تدفقات التجارة التونسية إلى كل شريك تتأثر بشكل غير متماثل علي الددى القصير فقط دون الطويل، ولكن فيما يقرب من نصف العينة كانت الآثار طويلة الددى متماثلة. دراسة (Mordecki,G., Miranda, R.,2019) 
درست هذه الورقة تقلبات سعر الصرف الحقيقي علي إجمالي الصادرات لكل من

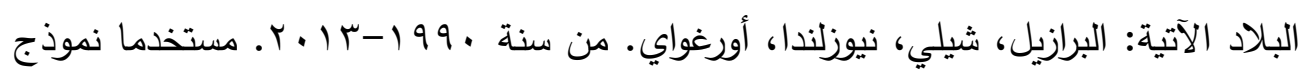
GARCH

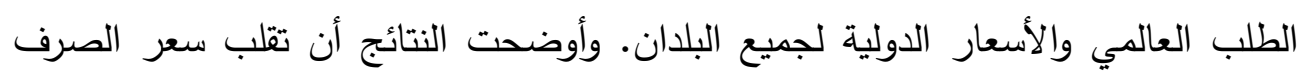

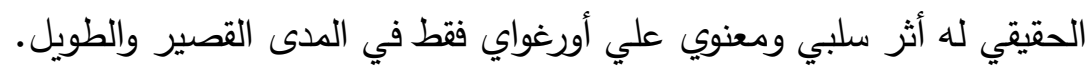

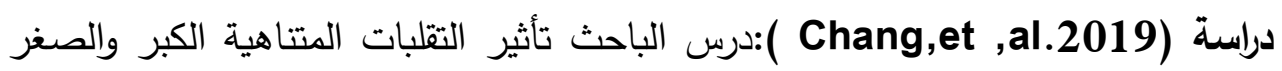

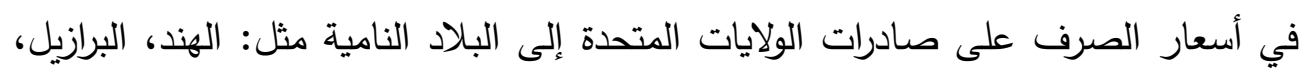

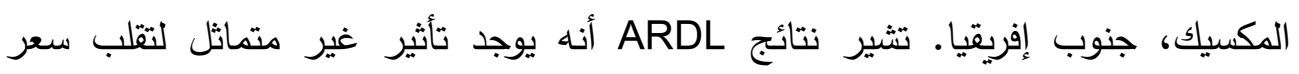

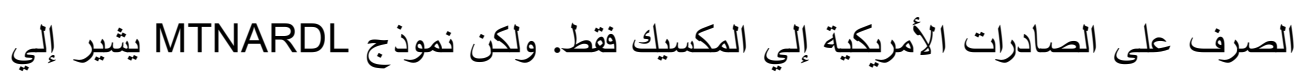

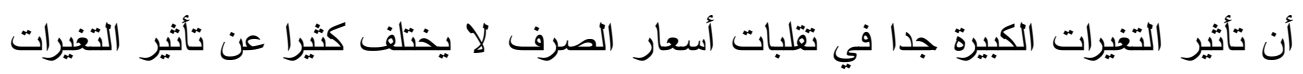

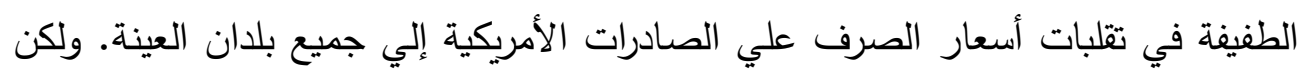

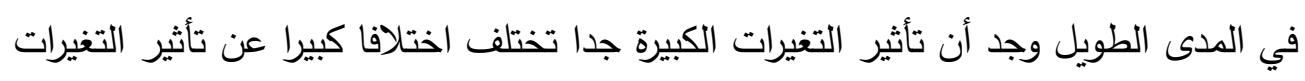
الصغيرة في تقلبات أسعار الصرف علي صادرات أمريكا إلي جميع بلدان العينة. دراسة (Upadhyaya, et, al.2020):

بحثت الدراسة في تأثير تقلبات أسعار الصرف على أداء الصادرات في جنوب

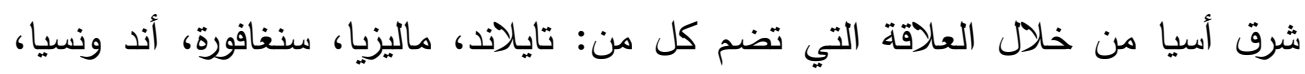

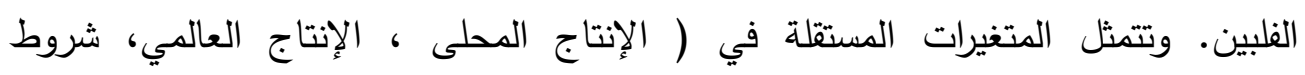

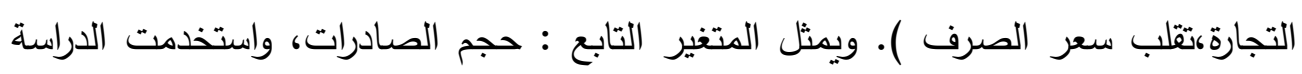

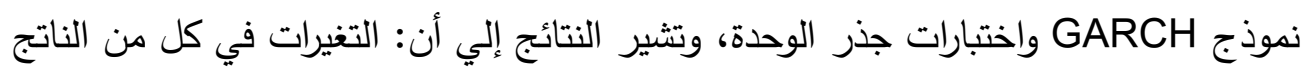

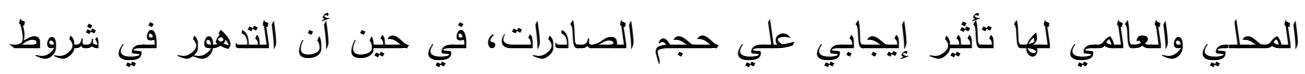

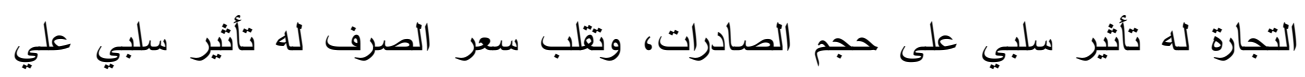
الصادرات في تلك البلاد. 9- قياس أثثر تقلبات سعر الصرف على الميزان التجاري لقطاع الأدوية المصري:

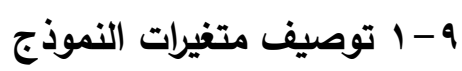


انطلاقا من النظرية الاقتصادية، والدراسات السابقة التي تم استعراضها، يتم توصيف المتغيرات كما في الجدول التالي :

جدول رقم (r) توصيف المتغيرات

\begin{tabular}{|c|c|c|c|c|}
\hline مصدر البيانات & قياسه & 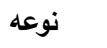 & اسم المتغير & 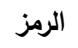 \\
\hline والإحصاء المركزي لتعبئة & صادرات الأدوية مطروحا منه واردات الأدوية & تابع & الميزان التجاري لقطاع الدواء المصري & TB \\
\hline بيانات البنك الدولي & 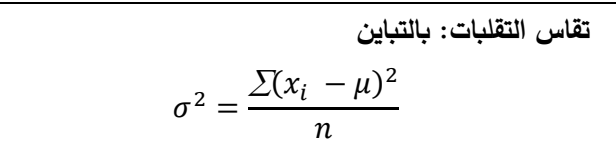 & 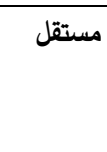 & تقلبات سعر الصرف & VER \\
\hline بيانات البنك الدولي & المقيمين في الاقتصادعأي ضرالي القيمة المضافة من قبل جميع المنتجين على المنتجات-الإعانات & 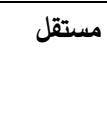 & 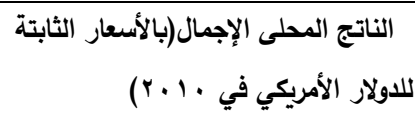 & GDP \\
\hline بيانات البنك الدولي & القيمة السوقية لجميع السلع والخدمات & مستقل & 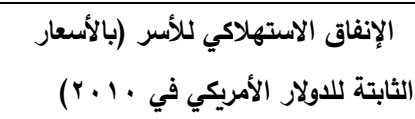 & EC \\
\hline بيانات البنك الدولي & يتحملها المستهلك؛ أسعار المستهلكين، النسبة المئوية في التكلفة التي & 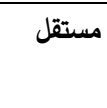 & $\begin{array}{r}\text { التضخم(الأسعار التي يدفعها } \\
\text { المستكون) }\end{array}$ & INF \\
\hline
\end{tabular}

جميع السلاسل الزمنية المستخدمة في تلك الدراسة عبارة عن بيانات سنوية للفترة ( •191 ا-

$$
\cdot(r \cdot 19
$$

$\mathrm{TB}=\mathrm{b}_{0}+\mathrm{b}_{1} *$ ver $+\mathrm{b}_{2} * \mathrm{ec}+\mathrm{b}_{3} * \mathrm{gdp}+\mathrm{b}_{4} * \mathrm{inf}++e$

العلاقة القياسية:

$$
\text { حيث أن: }
$$

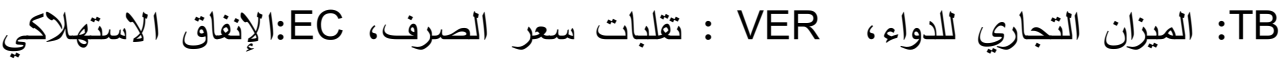

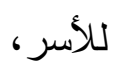

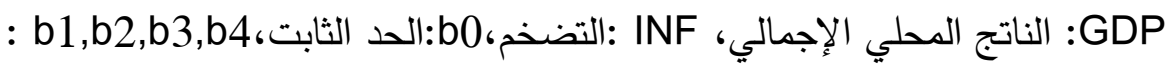
معاملات الانحدار للمتغيرات المستقلة، e: حد الخطأ العشوائي. 9-r اختبار السكون: Stationary Test (اختيار استقراريه متغيرات النموذج) 
تعد اختبارات السكون من الاختبارات الاستباقية للسلاسل الزمنية المراد تقدير العلاقة بين متغيراتها، ونقول بان بيانات السلاسل الزمنية مستقرة،عندما تكون تلك السلسلة مستقرة أفقيا حور المحور السيني (محور الزمن )، أي أن السلسلة تتذبذب حول وسط حسابي ثابت بابت لا يعتمد على اتجاه زمني،أي تكون السلسة الزمنية مستقرة بشكل تام) (Strictly .(Stationary يتمثل الفرض العدمى والبديل للاختبار كالتالي:

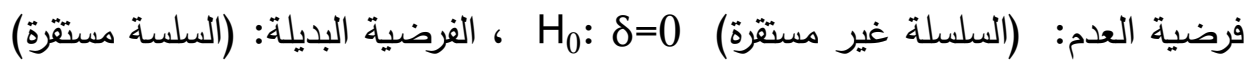
$\mathrm{H}_{1}: \delta<0$

والقرار يكون بمقارنة القيم المحسوبة لإحصاء الاختبار (t ) مع القيمة الجدولية لديكي -

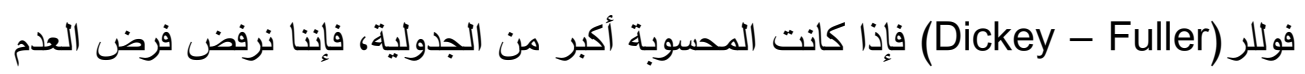

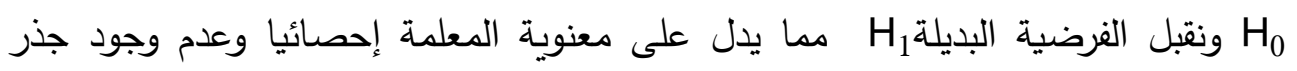
الوحدة (Unit Root) ) ؛ بمعنى أن السلسة الزمنية للمتغير المراد دراسته مستقرة(Stationary)، والعكس صحيح(يحيى، 1 ( • ب )

\begin{tabular}{|c|c|c|c|c|c|c|}
\hline & & & المستوي & & & الفرق الأ \\
\hline \multirow[t]{2}{*}{ المتغيرات } & \multirow{2}{*}{ القيمة الحرجة } & ثابت & ثابت واتجاه & بدون ثابت واتجاه & ثابت & ثابت واتجاه \\
\hline & & -2.948404 & -3.540328 & -1.950687 & -2.948404 & -3.544284 \\
\hline TB & \multirow{4}{*}{ قالمحسوبة } & 2.319265 & 0.05374 & 3.680185 & -1.776698 & $*-5.900743$ \\
\hline VER & & 0.967108 & -0.840706 & 2.118938 & $*-4.63061$ & \\
\hline GDP & & 3.19961 & 0.70475 & 3.686263 & -1.132335 & $*-3.82671$ \\
\hline EC & & 1.938978 & -0.640575 & 3.159401 & -2.818228 & $*-3.746255$ \\
\hline
\end{tabular}

والجدول التالي يوضح نتائج اختبارات السكون للمتغيرات باستخدام اختبار ديكي فولر الموسع، مستعينا ببرنامج (Eviews9 ). 
لجدول رقم (r) نتائج اختبارات السكون للمتغيرات باستخام ( ADF ): علامة: *= مستقر ، الفرض العدمى: يوجد جذر الوحدة، والبديل لا يوجد جذر الوحدة (السلسة مستقرة)

Eviews9 من إعداد الباحث بالاعتماد على مخرجات برنامج منسرة ومن معطيات الجدول السابق رقم (r) يتضح أن السلاسل الزمنية للمتغيرات،

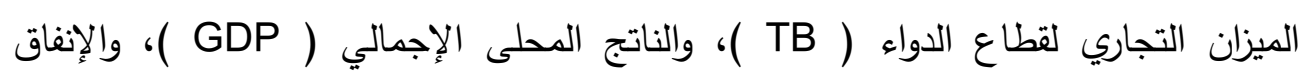

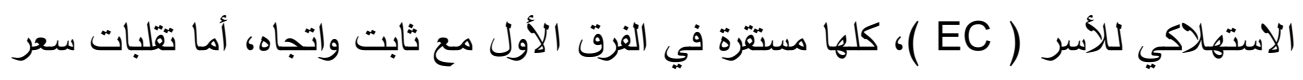
الصرف ( VER ) مستقر في الفرق الأول وثابت فقط، ولكن يتضح أن التضخم (INF) مستقر في المستوى مع ثابت فقط. يتبين من الفقرة السابقة استقرار السلاسل في الفرق الأول، عدا التضخم فهو مستقر في

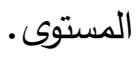
لذا نرفض الفرض العدمى، ونقبل الفرض البديل (الفرض البديل: عدم وجود جذر الوحدة،أي السلسة مستقلة). : ARDL

نلاحظ من نتائج اختبارات السكون السابقة أن السلاسل مستقرة في كل من: المستوى،

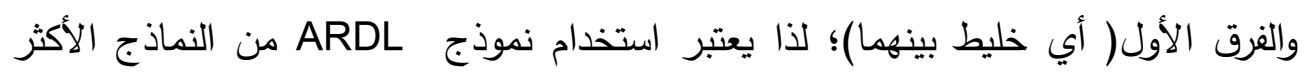

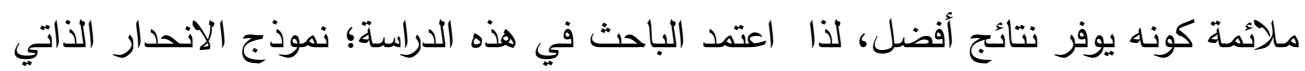

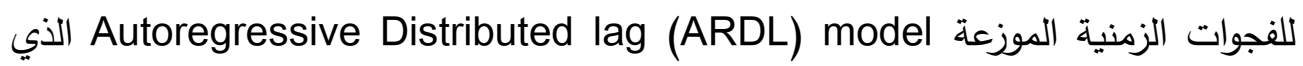

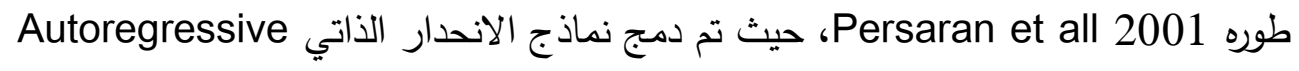
ونماذج فترات الإبطاء الموزعة Distributed lag model,AR(P) المنهجية، تكون السلسلة الزمنية دالة في إبطاء قيمها، وقيم المتغيرات التقسيرية الحالية، وإبطائها بفترة واحدة أو أكثر . 
9- - - $1-9$

يعتمد نموذج ARDL على المعادلة التالية والتي تمثل متغيرات النموذج : $\begin{aligned} \Delta \mathrm{TB}=\theta_{0}+ & \sum_{\mathrm{i}=1}^{\mathrm{n}} \beta_{1} \Delta \mathrm{TB}_{\mathrm{t}-\mathrm{i}}+\sum_{\mathrm{i}=1}^{\mathrm{n}} \beta_{2} \Delta \mathrm{VER}_{\mathrm{t}-\mathrm{i}}+\sum_{\mathrm{i}=1}^{\mathrm{n}} \beta_{3} \Delta \mathrm{EC}_{\mathrm{t}-\mathrm{i}}+\sum_{\mathrm{i}=1}^{\mathrm{n}} \beta 4 \Delta G D P t- \\ & i+\sum_{\mathrm{i}=1}^{\mathrm{n}} \beta_{5} \Delta \mathrm{INF}_{\mathrm{t}-\mathrm{i}}+\lambda_{1} \mathrm{~TB}_{\mathrm{t}-1}+\lambda_{2} \mathrm{VER}_{\mathrm{t}-1}+\lambda_{3} \mathrm{EC}_{\mathrm{t}-1}+\lambda_{4} \mathrm{GDP}_{\mathrm{t}-1}+\lambda_{5} \mathrm{INF}_{\mathrm{t}-1}+\varepsilon_{\mathrm{t}}\end{aligned}$ حيث أن:- TB: الميزان التجاري للدواء، VER : تقلبات سعر الصرف، EC:الإنفاق الاستهلاكي للأسر،GDP:الناتج المحلي الإجمالي، INF:التضخم، ه: الفرق الأول

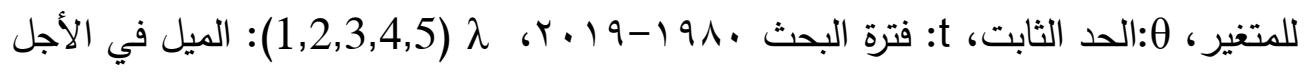
الطويل، - q-r-r - اختبار فترات الإبطاء المثلى للنموذج:

يوضح الثكل التالي فترات الإبطاء المثلى حسب معيار ( Sch ) Schwarz Oriteria (top 20 models)

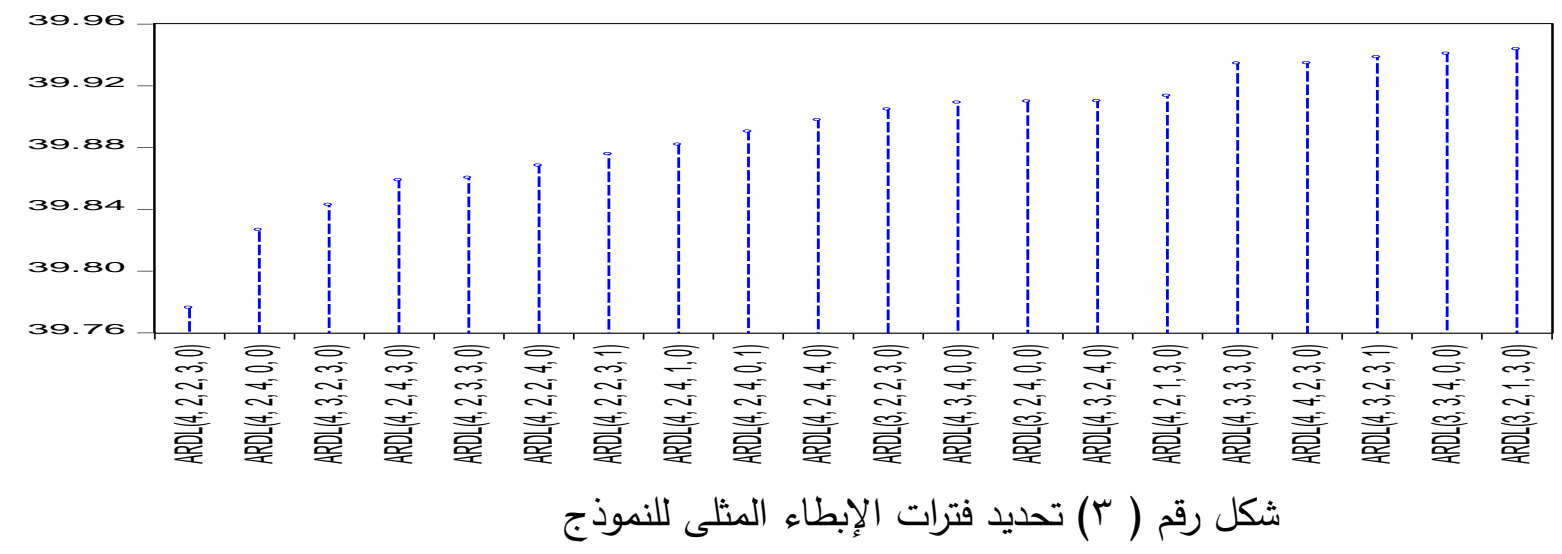

Eviews9 من إعداد الباحث بالاعتماد على برنامج ويتضح من الثكل السابق أن أفضل نموذج حسب معيار شوارز هو( 4,2,2,3,0 .ARDL( 9-r-r تقدير الأثر في الأجلين القصير والطويل باستعمال نموذج ARDL: 
نقوم الآن بتقدير النموذج وفقا للخطوات التالية: 9-r-r-1 اختبار التكامل المشترك وفق منهج الحدود (F - Bound Test): يستخدم نموذج ARDL اختبار الحدود (F - Bound Test) للتأكد من: وجود أو عدم وجود تكامل مشترك بين المتغيرات، حيث أن الفرض العدمى ينص على أنه لا يوجد تكامل مشترك بين المتغيرات، ضد الفرض البديل الذي ينص على وجود تكامل مشترك بين المتغيرات، و طبقا لهذا الاختبار إذا كانت قيمة F المحوبة أكبر من قيمة الحد الأعلى؛ فسيتم رفض الفرض العدم، وقبول الفرض البديل الذي ينص على وجود تكامل مشترك بين المتغيرات، أما إذا كانت قيمة F المحسوبة أقل من قيمة الحد الأدنى، يتم قبول الفرض العدم، بعدم وجود علاقة تكامل مشترك، أي عدم وجود علاقة توازنية بين المتغيرات، أما إذا كانت قيمة F المحسوبة تقع بين الحد الأدنى والحد الأعلى، في هذا الحالة تكون النتائج غير محددة، وبالتالي لا يمكن اتخاذ قرار بأن هناك تكامل مشترك بين المتغيرات من عدمه. BOUND Test جدول رقم (؛ ) نتائج اختبار التكامل المشترك باستخدام منهج الحدود

\begin{tabular}{|c|c|c|}
\hline Test Statistic & Value & $\mathrm{k}$ \\
\hline F-statistic & 10.33774 & 5 \\
\hline \multicolumn{3}{|c|}{ Critical Value Bounds } \\
\hline المعنوية Significance & I0 Bound الحد الأدنى I0 & $\begin{array}{c}\text { الحد I1 Bound } \\
\text { الأعلى }\end{array}$ \\
\hline $10 \%$ & 2.08 & 3 \\
\hline $5 \%$ & 2.39 & 3.38 \\
\hline $2.5 \%$ & 2.7 & 3.73 \\
\hline $1 \%$ & 3.06 & 4.15 \\
\hline
\end{tabular}

Eviews9 من إعداد الباحث بالاعتماد على مخرجات برنامج

وبإمعان النظر في الجدول السابق نجد أن: قيمة (F-statistic ) البالغة ( rr, •(1) أكبر من جميع قيم الحد الأعلى (11)؛ وهذا يعنى وجود تكامل مشترك بين 
متغيرات النموذج، وبالتالي نرفض فرض العدم، ونقبل الفرض البديل، بوجود علاقة توازنية

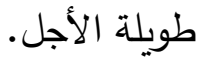

\section{: ECM (EM-r-r-r}

بعد ما تأكدنا من وجود علاقة توازنية طويلة الأجل، ننتقل إلى تقدير وتحليل الآثار قصيرة وطويلة الأجل، كما في الجدول التالي:

يوضح الجدول رقم (0 ) تقدير العلاقة في الأجل القصير ، بينما يوضح الجدول رقم(؟ ) تقدير العلاقة طويلة الأجل. جدول (0) تقدير العلاقة في الأجل القصير

\begin{tabular}{|c|c|c|c|c|}
\hline Prob. المعنوية & t-Statistic & Std. Error & Coefficient المعاملات & Variable المتغير/ت \\
\hline $\mathbf{0 . 0 3 7 0}$ & -2.234522 & 0.104835 & -0.234255 & $D(T B(-1))$ \\
\hline 0.0000 & -5.530429 & 0.109131 & -0.603539 & $D(T B(-2))$ \\
\hline 0.0027 & 3.416691 & 0.115001 & 0.392924 & $D(T B(-3))$ \\
\hline 0.0000 & 0.000000 & 12194055.736995 & 34015941.375299 & $D(V E R)$ \\
\hline 0.0000 & 0.000000 & 16824629.422654 & 93732351.675310 & $D(\operatorname{VER}(-1))$ \\
\hline 0.0581 & 2.010257 & 0.007727 & 0.015534 & $D(E C)$ \\
\hline 0.0725 & 1.896016 & 0.006135 & 0.011631 & $D(G D P)$ \\
\hline 0.8025 & 0.253469 & 0.006341 & 0.001607 & $D(G D P(-1))$ \\
\hline 0.0001 & -5.037036 & 0.006308 & -0.031771 & $D(G D P(-2))$ \\
\hline 0.0000 & 0.000000 & 2339111.635864 & -6199373.013478 & $D(I N F)$ \\
\hline 0.0000 & -7.316438 & 0.034314 & -0.251054 & معلمة تصحيح الغطاء \\
\hline
\end{tabular}

$\Delta \mathrm{TB}=\theta_{0}+\sum_{\mathrm{i}=1}^{\mathrm{n}} \beta_{1} \Delta \mathrm{TB}_{\mathrm{t}-\mathrm{i}}+\sum_{\mathrm{i}=1}^{\mathrm{n}} \beta_{2} \Delta \mathrm{VER}_{\mathrm{t}-\mathrm{i}}+\sum_{\mathrm{i}=1}^{\mathrm{n}} \beta_{3} \Delta \mathrm{EC}_{\mathrm{t}-\mathrm{i}}+\sum_{\mathrm{i}=1}^{\mathrm{n}} \beta 4 \Delta G D P t-$ $i+\sum_{\mathrm{i}=1}^{\mathrm{n}} \beta_{5} \Delta \mathrm{INF}_{\mathrm{t}-\mathrm{i}}+\varnothing \mathrm{ECT}_{\mathrm{t}-\mathrm{i}+\varepsilon_{\mathrm{t}}}$

ECT 
جدول رقم(؟) تقدير العلاقة في الأجل الطويل

\begin{tabular}{|c|c|c|c|c|}
\hline Prob.المعنوية & t-Statistic & Std. Error & $\begin{array}{c}\text { المعاملات } \\
\text { Coefficient }\end{array}$ & المتغيراتVariable \\
\hline 0.8072 & -0.247313 & 64015845.969320 & -15831972.688818 & تقلبات سعر الصرفVER \\
\hline 0.0028 & -3.399958 & 0.028432 & -0.096669 & EC الإنفاق الاستهلاكي EC \\
\hline 0.0055 & 3.115055 & 0.019625 & 0.061132 & GDPالناتج المحلي الإجمالي \\
\hline 0.0110 & -2.803678 & 8917344.099811 & -25001363.422379 & Iلالتضخم INF \\
\hline 0.0021 & 3.529196 & 633032645.315953 & 2234096352.232961 & الثابتC \\
\hline
\end{tabular}

من إعداد الباحث بالاعتماد على مخرجات برنامج Eviews9

Cointeq $=$ TB $-(-15831972.6888 *$ VER $-0.0967 *$ EC + 0.0611*GDP $-25001363.4224 * \mathrm{INF}+2234096352.2330$

وبإمعان النظر في الجدول رقم (0 ) الخاص بالأجل القصير بأن :

1- هناك استجابة قصيرة الأجل موجبة ومعنوية ، بين كل من المتغيرات المستقلة الآتية :-

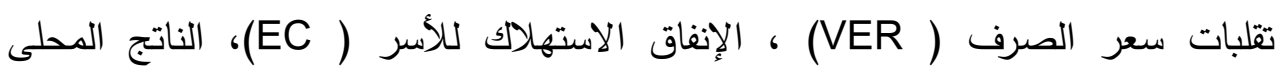

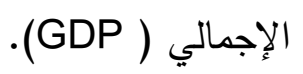

وبين الميزان الجاري لقطاع الدواء(TB ) كمتغير تابع.

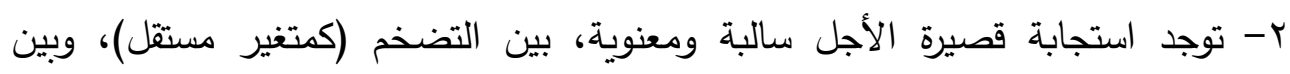
الميزان الجاري لقطاع الدواء(TB ) كمتغير تابع.

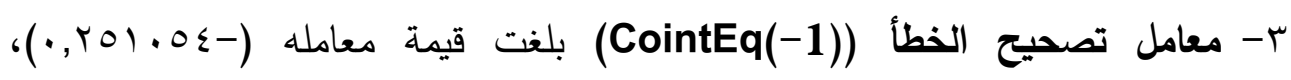
باحتمالية (....)، ومع توفر شرطي السالبية والمعنوية، وهذان هما الشرطان الضروري والكافي؛ فإن النموذج يتجه نحو تحقيق التوازن في الأجل الطويل؛ أي أن

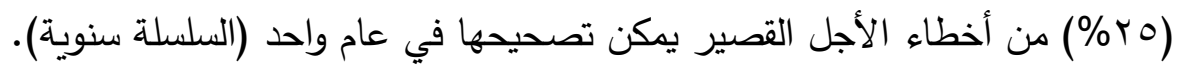

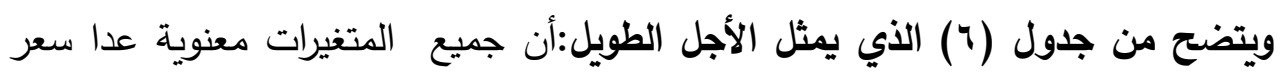

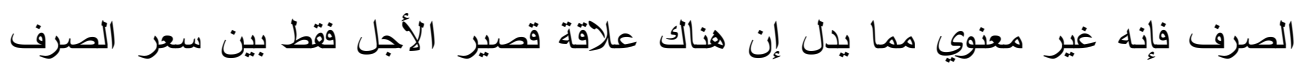

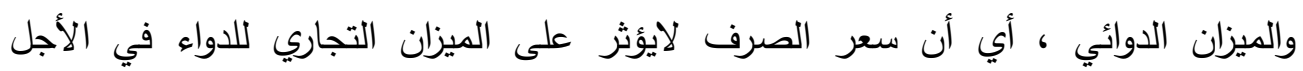
الطويل، وتفسيره من الناحية الاقتصادية أن الدواء سلعة ضرورية لا يمكن الاستغناء عنها، و 
عديمة المرونة أي مهما تغير السعر فلا يؤثر على الكمية، وبالتالي فإن الميزان التجاري

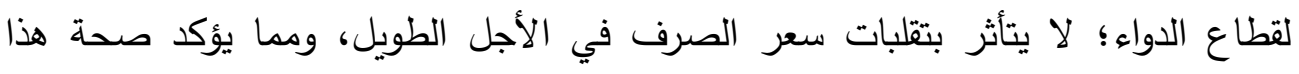

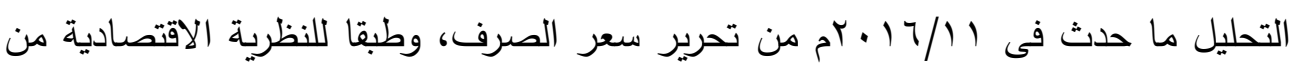

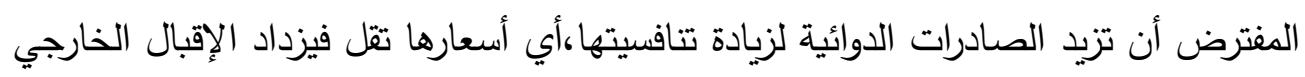
عليها أي تزيد صادراتها، ولكن دعونا نلقي نظرة علي الجدول التالي ، لنري هل انطبقت

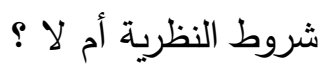

جدول رقم (V) صادرات وواردات الأدوية المصرية للفترة من (1 (1) ب-

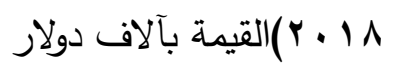

\begin{tabular}{|c|c|c|c|}
\hline واردات الأدوية المصرية & صادرات الأدوية المصرية & سعر الصرف & عام \\
\hline $1,910,99$. & $r M \Lambda, Y \leq 0$ & $1 \cdot, \cdot r$ & r.17 \\
\hline$r, \backslash \wedge V, \wedge q 9$ & $r \vee O, \wedge \leq q$ & $Y v, Y A$ & r.IV \\
\hline$r, r \cdot \Lambda, \lambda \vee \wedge$ & $r \leqslant T, O \Lambda Y$ & $I V, Y Y$ & $r .11$ \\
\hline
\end{tabular}

من إعداد الباحث بالاعتماد علي بيانات البنك الدولي ومركز التجارة العالمي

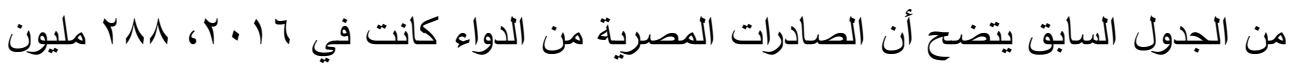

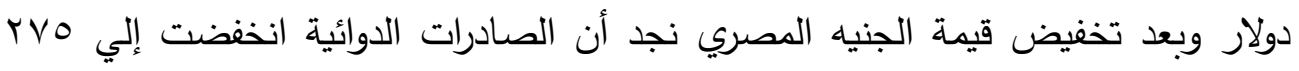

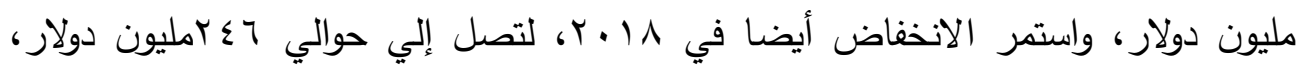

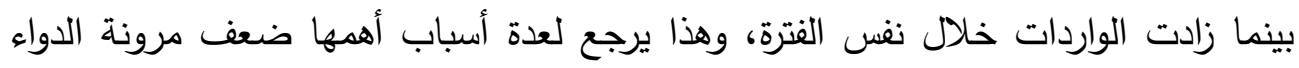
كسلعة،وأن معظم مكونات الدواء مستوردة من الخارج.

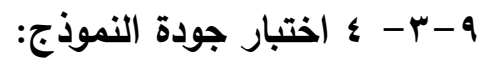

للتأكد من جودة النموذج، يتم الاعتماد على: اختبارات الارتباط الذاتي للأخطاء العشوائية،

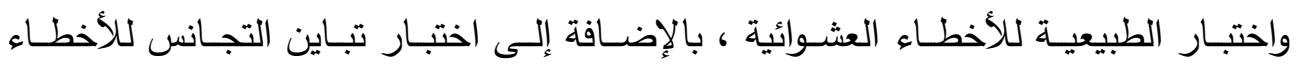

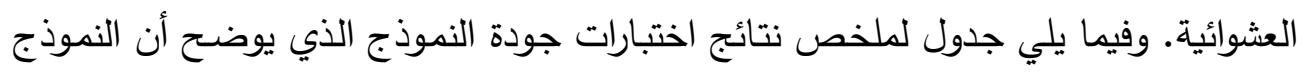
مقبول من الناحية الإحصائية ويمكن الاعتماد على نتائجه في عملية التقدير. 
جدول (^) ملخص نتائج اختبارات جودة النموذج

\begin{tabular}{|c|c|c|}
\hline 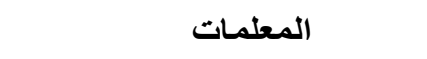 & 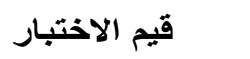 & القرار \\
\hline \multicolumn{2}{|c|}{$\begin{array}{l}\text { Breusch-Godfrey Serial Correlation LM Test: } \\
\qquad \begin{array}{l}\text { إختبار الإتباط الذاتي }\end{array}\end{array}$} & \multirow{3}{*}{ 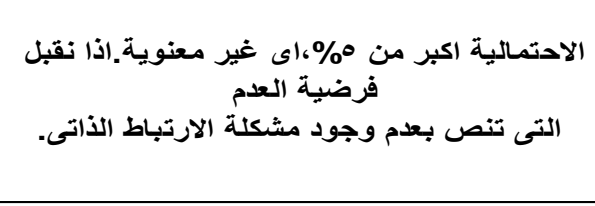 } \\
\hline Prob. F & 0.4658 & \\
\hline Prob. Chi-Square & 0.3663 & \\
\hline \multicolumn{2}{|c|}{ Heteroskedasticity Test: ARCH إختبار ثبات تجانس التباين } & \multirow{2}{*}{ 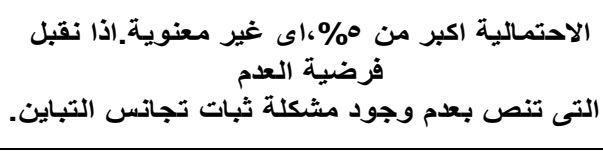 } \\
\hline $\begin{array}{c}\text { Prob. F } \\
\text { Prob Chi-Sauare }\end{array}$ & 0.2281 & \\
\hline \multicolumn{2}{|c|}{ إختبار التوزيع الطبيعي:HistograM - Normality test } & \multirow{3}{*}{ 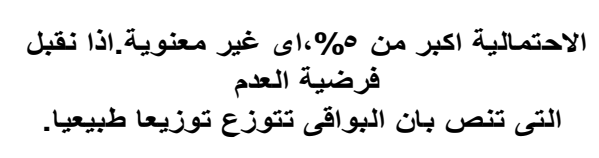 } \\
\hline Jarqe-bera & 0.685182 & \\
\hline prob. & 0.709929 & \\
\hline
\end{tabular}

Eviews9 من إعداد الباحث بالاعتماد على مخرجات برنامج

9-r-ه اختبار استقراريـه النموذج (Stability test ).

يعد هذا الاختبار من ضمن أهم الاختبارات في هذا المجال ـ لأنه يمكنتا معرفة أمرين

: ا-لا يوجد أي تغير هيكلي في البيانات. ץ - مدى انسجام واستقرار المعلمات القصيرة

الأجل مع طويلة الأجل. ويعد هذا الاختبار من الاختبارات الهامة المستخدمة والمصاحبة

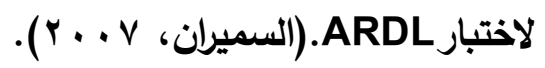

أ-الاختبار الخاص بالمجموع التراكمي للبواقي:

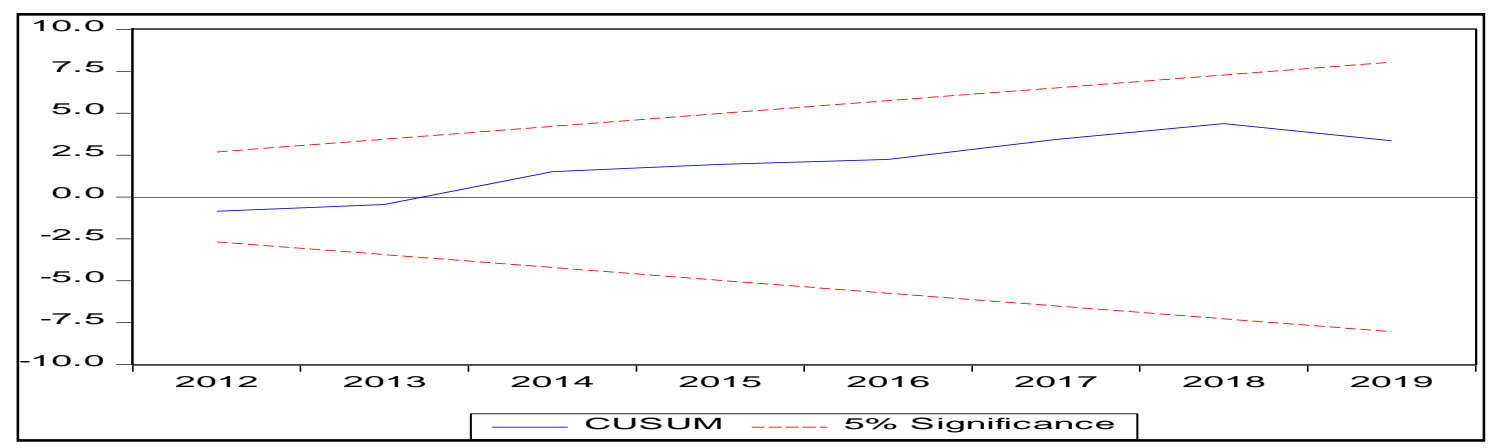


شكل رقم (ء ) المجموع التراكمي للبواقي (CUSUM)

ب- الاختبار الخاص بالمجموع التراكمي لمربعات البواقي:

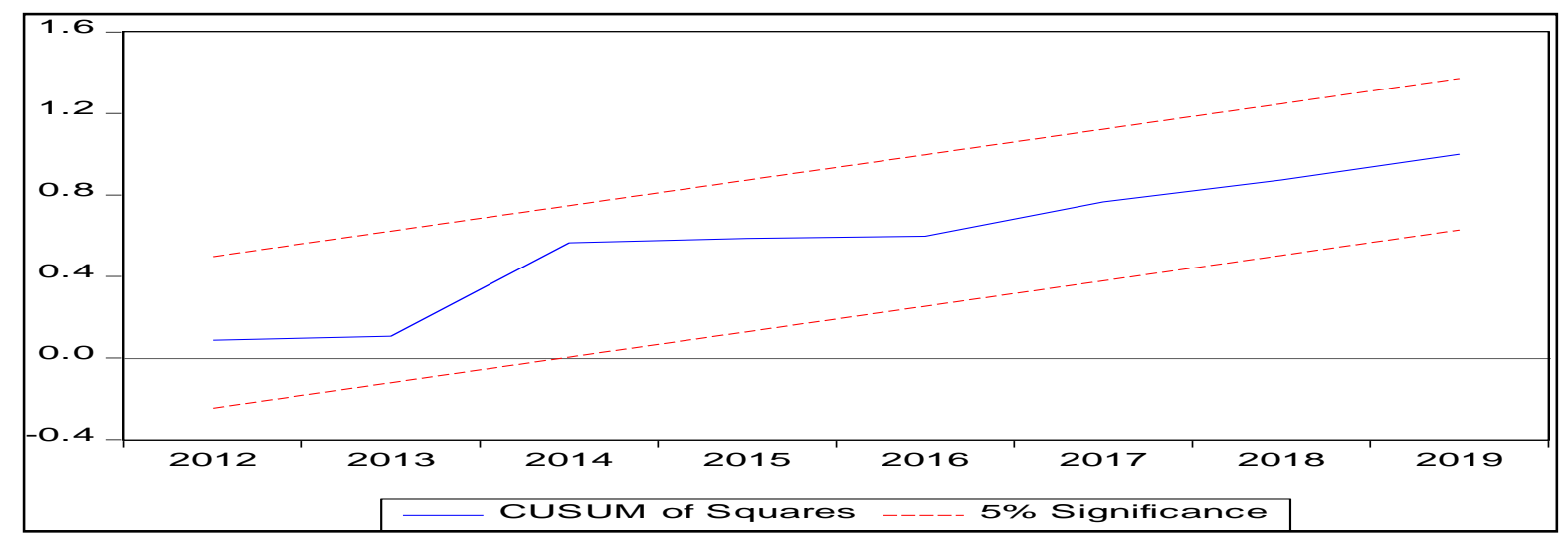

شكل رقم (0) المجموع التراكمي لمربعات البواقي (CUSUMSQ)

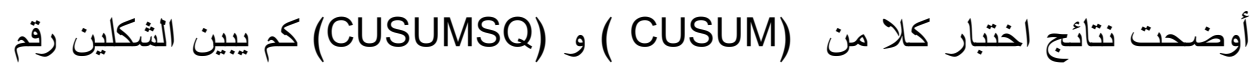

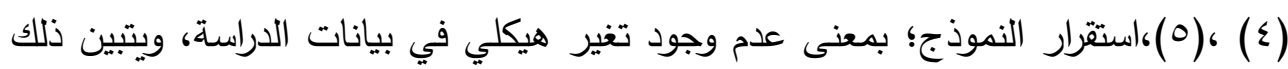
من خلال وقوع خط البيانات المستخدمة ضمن خطى (الددود) الجدولية للاختبارين، حيث

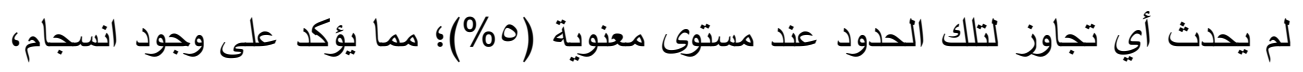

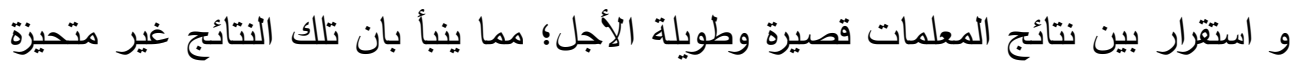
ويعتد بها . و المان. 
- النتائج: -

أ - أ في الأجل القصير:

• المتغيرات المستقلة: ( تقلبات سعر الصرف، ألإنفاق الإستهلاكي للأسر، الناتج

المحلي الإجمالي)؛ لها تأثير موجب ومعنوي، على الميزان التجاري لقطاع الدواء

المصري، أما التضخم؛ فتأثيره سالب ومعنوي على الميزان التجاري لقطاع الدواء

المصري.

• معلمة تصحيح الخطأ جاءت معنوية وسالبة؛؛ أي أن الانحرافات في الأجل القصير

تتجه للتوازن في الأجل الطويل.

ب - في الأجل الطويل:

1- تقلبات سعر الصرف سالب وغير معنوي، سالب لا يتفق مع النظريـة الاقتصادية

حيث إن انخفاض قيمـة العملة المحلية (مقابل ارتفاع سعر الصـرف الأجنبي) يؤدى إلى انخفاض تكاليف عوامل الإنتاج بالداخل مقارنه بالعالم الخارجي، وبالتالي انخفاض أسعار الصـادرات مقارنــة بالعـالم الخـارجي؛ ممـا يزيـــ الطلب على الصــادرات المحليـة، وبالتـالي تحسين الميزان التجاري، أما من حيث المعنويـة فالتأثير علي ميزان القطاع الدوائي لـه شأن خاص؛ حيث يعتبر الدواء سلعة ضرورية لا ينطبق عليها قانون العرض والطلب؛ فهي سلعة عديمة المرونة.

r- الإنفاق الاستهلاكي للأسر لـه تأثير سالب و معنوي أقل من ه\% على الميزان التجـاري الدوائي؛ أي زيـادة الإنفاق الاستهلاكي للأسـر بوحدة واحدة فإن الميزان الدوائي ينخفض ب (97V • . , ) )؛ وهذا يتفق مع النظريـة الاقتصادية؛ حيث إن زيادة الطلب المحلي يؤدى بدوره إلى انخفاض الكميـة المخصصـة للتصدير ، وبالتـالي نقص الصـادرات وزيـادة العجز في الميزان التجاري ، وذلك يوضح الخلل الهيكلي في القطاع الإنتاجي المحلي. 


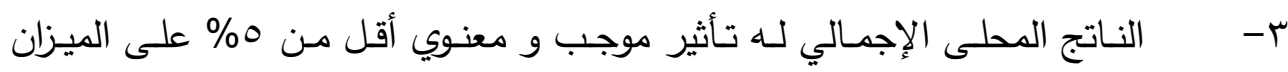
التجاري الدوائي، أي زيادة الناتج المحلي الإجمالي بوحدة واحدة فإن الميزان التجاري الدوائي

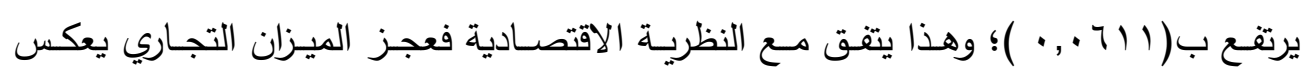

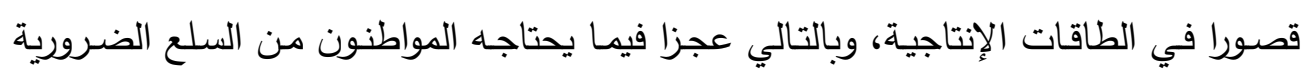

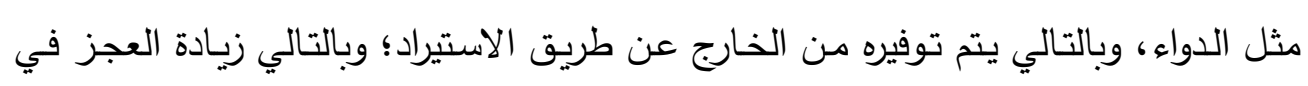
الميزان التجاري، والعكس صحيح.

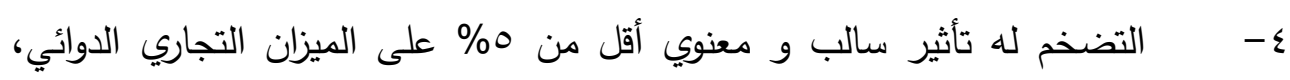

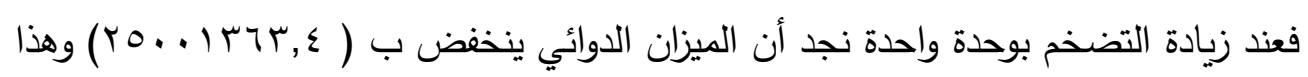

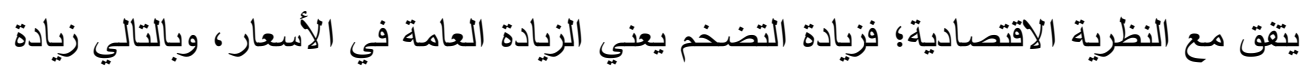

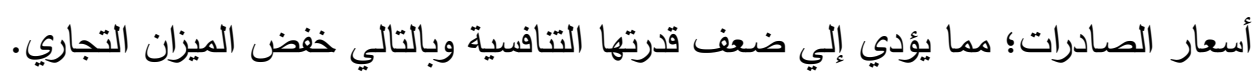

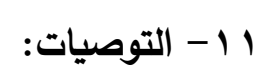

1- عمل دراسات، مسبقة ومستفيضة ومرتبطة بالواقع؛ لإنجاح سياسة تغير سعر الصرف، ومدي ملائمتها للقطاعات الحيوية للاقتصاد الدصري. r- الترشيد الاستهلاكي للدواء، في كافة الجوانب، وخاصـة: أدوية التأمين الصحي، ونفئة الدولة.

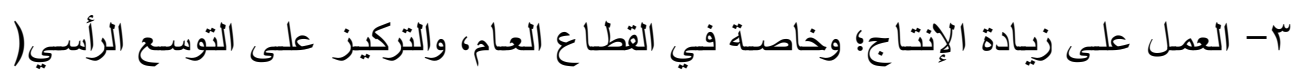

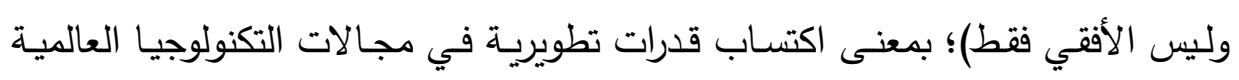
الحديثة (مثل تخليق المادة الخام- التكنولوجيا الحيوية - الثكل الصيدلي المتطور ). ع- العمل المثر للحد من زيادة معدلات التضخم بكافة السبل. 


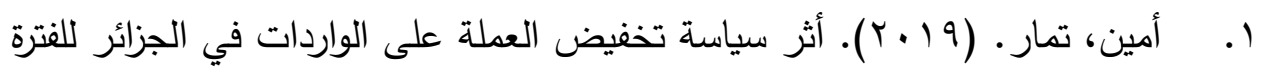

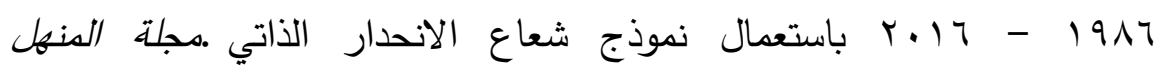
الاقتصادي: جامعة الثعيا حمه لخضر الوادي - كلية العلوم الاقتصادية والتجارية

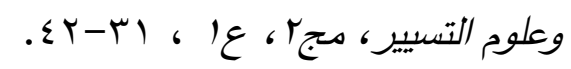

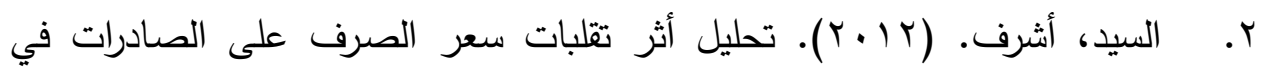
جمهورية مصر العربية .مجلة التجاة والتهويل: جامعة طنطا - كلية التجارة، ع ع علئ

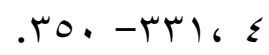

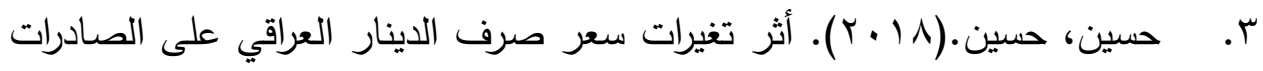

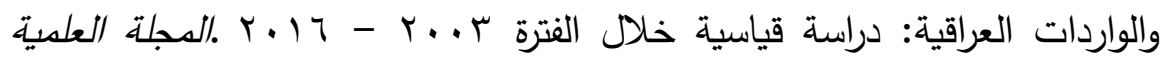

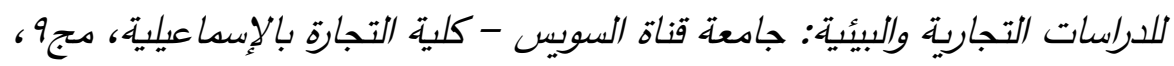
$. \wedge \cdot 0-V V V \cdot r \varepsilon$

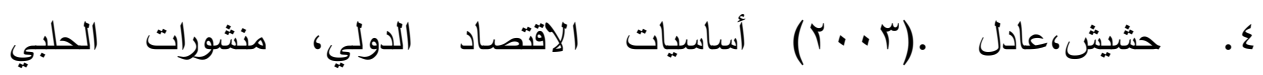
الحقوقية، لبنان

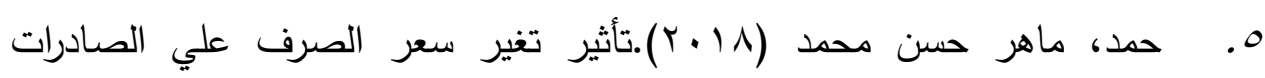
والواردات في مصر.رسالة ماجستير،كلية الاقتصاد والعلوم الإدارية،جامعة الازهر كغزة.

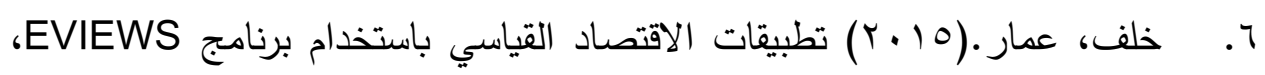
الطبعة الأولى، دار الدكتور للعلوم الادارية والاقتصادية والعلوم الأخرى، بغداد.

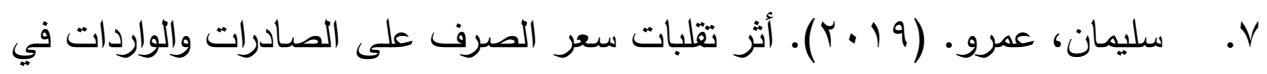

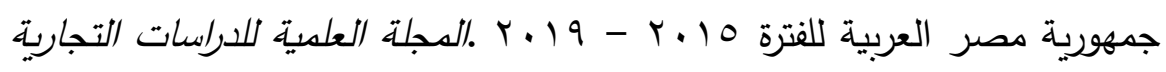

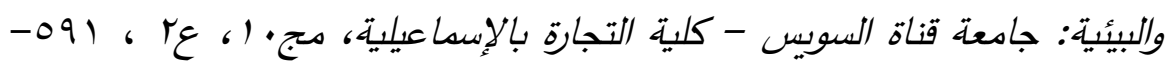
די.

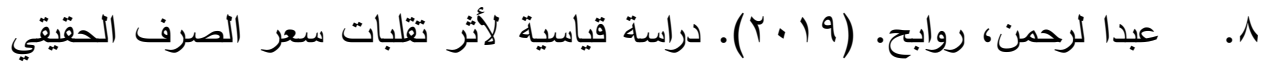

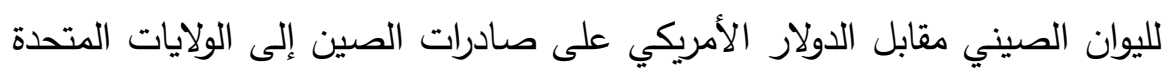




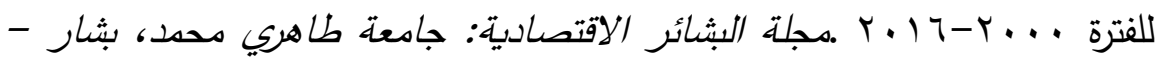

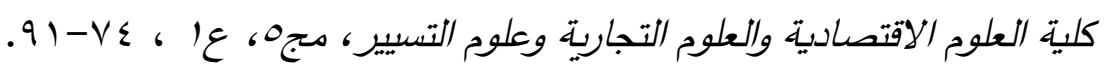

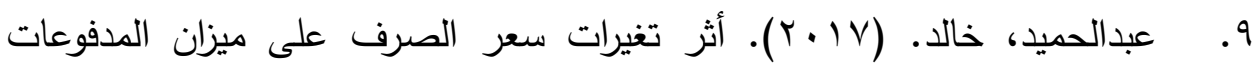

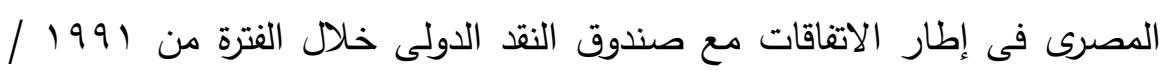

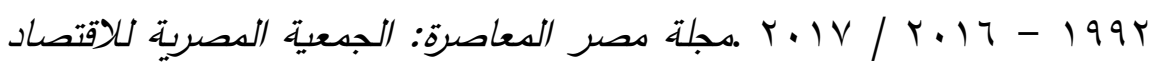

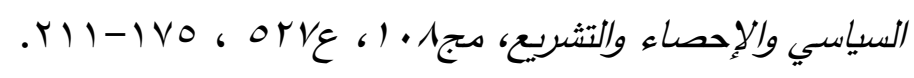

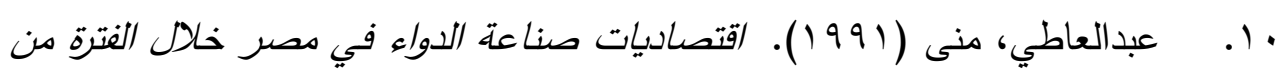

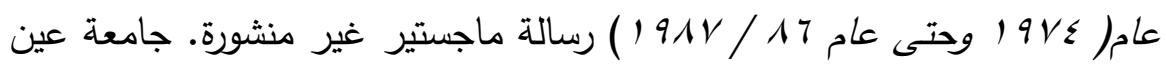
شمس، القاهرة.

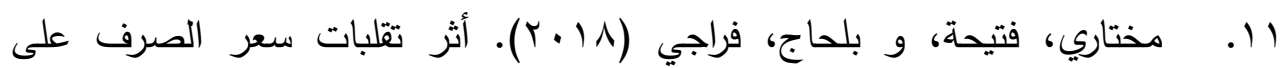

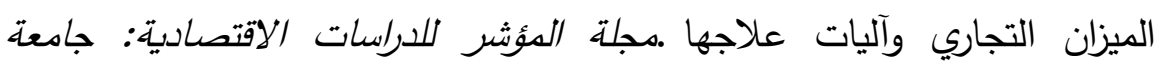
طاهي محد، بثار - كلية العلوم الاقتصادية والعلوم التجارية وعلوم التسبير -

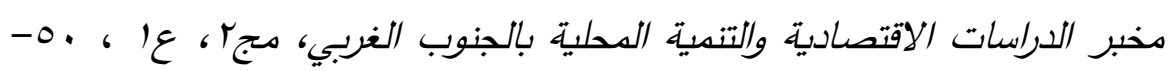
.71 r ا. يحيى،إيناس. (7 ( ץ).اختبار جذر الوحدة لاستقرار إجمالي الصادرات بجمهورية

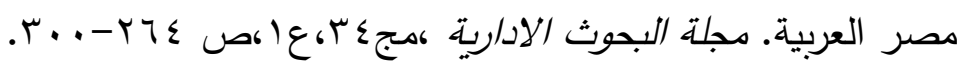

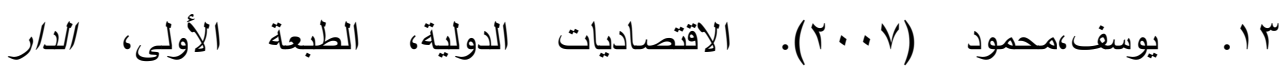
الجامعية ،الإسكندرية،مصر . 
1. Ayobami, o.t.(2019). Exchange Rate Volatility and the Performance of anufacturing Sector in Nigeria (1981 - 2016). African Journal of Economic Review, 7(2), 27-41

2. Bahmani-Oskooee, M., \& Nouira, R. (2019). On the impact of exchange rate volatility on Tunisia's trade with 16 partners: an asymmetry analysis. Economic Change and Restructuring, 1-22

3. Chang, B.H.,Rajput,S.K,O.,\&Bhutt,N.A.(2019).Impact of exchang rate volatility on the US export: a new evidence from multiple threshold nonlinear ARDL model. Journal of international commerce,Economics and Policy,2019,10.02:1950009.

4. Chaudhry, A. F., \& Yuce, A. (2019). Effects of Canadian Exchange rate Volatility on Imports and Exports. Int J Econ Manag Sci, 8(561),

5. Emmanuel, D. K. (2019). The effects of exchange rate volatility on foreign trade in Ghana. Journal of Economics Library, (4),6, 267-286.

6. Mmelesi, K., Daw, O. D., \&Mongale, I. P. (2019). The impact of exchange rate on clothing exports in South Africa.

7. Mordecki, G., \& Miranda, R. (2019). Real exchange rate volatility and exports: A study for four selected commodity exporting countries. Panoeconomicus, (4)66, 411-437

8. Motlagh, S. N., Hadian, M., Mousavi, A., Alipour, S., Jahangiri, R., \& Rostami, M. A. (2018). Investigating the Effects of Exchange Rate Fluctuations on the Import and Export of Medicine in Iran from 2001 to 2014. Shiraz E-Medical Journal, 19(10).

9. Saqib, a. (2019). Exchange rate volatility and pakistan trade flows: new evidence of symmetric and asymmetric effect (doctoral dissertation, capital university).

10. Sugiharti, L., Esquivias, M. A., \& Setyorani, B. (2020). The impact of exchange rate volatility on Indonesia's top exports to the five main export markets. Heliyon, (1),6, e03141.

11. Thuy, V. N. T., \& Thuy, D. T. T. (2019). The impact of exchange rate volatility on exports in Vietnam: A bounds testing approach. Journal of Risk and Financial Management, 12(11), 6.

12. Tumturk, o. (2018). The impact of exchange rate volatility on export flows in developing countries. Uluslararasi iktisadi ve idari

13. incelemeler dergisi, (23), 79-94.

14. Upadhyaya, K. P., Dhakal, D., \& Mixon Jr, F. G. (2020). Exchange Rate Volatility and Exports: Some New Estimates from the Asean-5. The Journal of Developing Areas, (1)54. 